\title{
Observations on the Reactions of Marine Plankton to Light.
}

By

\author{
G. M. Spooner, M.A., \\ Assistant Naturalist at the Plymouth Laboratory.
}

With 22 Figures in the Text.

\section{CONTENTS.}

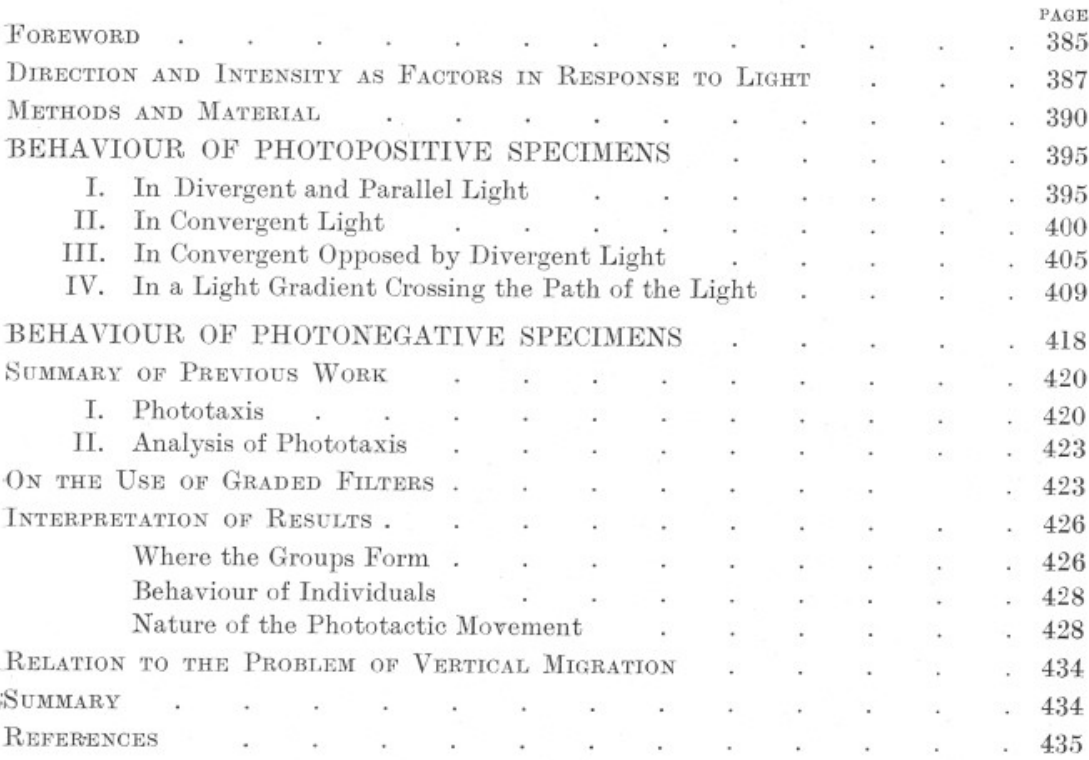

\section{FOREWORD.}

That light is among the more influential elements in the environment of the smaller marine organisms is widely recognised. While laboratory investigation has revealed its kinetic action in specific ways, its capacity for stimulating behaviour responses, and its orientating action on directed movement, the observations of field-workers are providing a growing body of evidence that light does indeed act as an important factor in the bionomics of species in the wild.

The effect of changes in illumination on vertical distribution is an 
obvious case in point. Now, this line of investigation, as is characteristic of such marine ecological studies, deals essentially with the movement of populations, or groups. The sort of conclusion to be derived from the results is that changes in the distribution of a population correlate significantly with changes in illumination. In practice, it is usually possible to go beyond generalisations of this kind, but doing this involves assumptions concerning the behaviour of individuals composing the group. Indeed, the closer the correlation, the more necessary it becomes to think in terms of the behaviour of individuals. This is a general necessity in the study of populations which form quite unorganised groups, since the behaviour of the whole is merely a reflection of the units composing it.

Hence appears a demand for knowledge of the behaviour of individual plankton animals. Since, however, insurmountable difficulties exist in the direct observation of these animals in their natural habitats, there is little possibility of obtaining the required information other than by investigation in the laboratory. To offset the advantages of controlled experiment, laboratory conditions, always more or less restricted and unnatural, are particularly so in the case in point, and more than usual care has to be exercised in ascribing significance to results obtained under them.

Still, granted that the behaviour of a population is to be rendered intelligible by knowledge of what the individuals composing it are doing, and granted that the behaviour of individuals in the laboratory bears at least. some kind of ascertainable relation to that of animals in the wild, it is concluded that data derived from the laboratory is not altogether without ecological value.

Turning now to what can be observed with regard to plankton animals confined in glass containers, one has to admit that the behaviour is, for the most part, featureless. There is little amongst the varied contrasts and changes to which the animals may be subject that can modify, or give added direction and coherence to their activity. Consequently, particular significance must be attached to any factor of the environment which. exerts consistent marked effects. It so happens that light proves to be just such a factor. Sudden changes in light intensity may produce shock reactions as readily as mechanical contact, while the clustering on the lighted side of glass containers is familiar to all who have had anything to do with plankton. Since, in the laboratory, the behaviour is perhaps more subject to conditions of illumination than to those of any other single factor, there is a maximum scope for experiment if behaviour in relation to light is chosen for study. This consideration is entirely independent of what has been said above with respect to the evident importance of light in nature. There is thus a twofold incentive for the study of behaviour in relation to light in marine organisms. 


\section{DIRECTION AND INTENSITY AS FACTORS IN RESPONSE} TO LIGHT.

One of the most readily noticed characteristics of collections of small marine animals is the formation of groups heading towards (or away from) the light. In any glass container a concentration of animals will be found on that side which faces a window, or artificial light-source, as the case may be. This applies to a great range of forms from various phyla. At the same time a greater or lesser concentration, of the same or different species, may occur on the opposite side of the container, in the part furthest from the source. The former group consists of individuals which move more or less directly up to the bright region where they collect and which at this stage may be simply called "positive," the latter of individuals which keep away from the source and may be called " negative." This grouping in relation to simply-defined conditions of illumination provides a suitable starting-point for more detailed study of the influence of light on the behaviour of the animals concerned.

Observers of this photopositive and photonegative behaviour are generally soon led to enquire how far the animals are influenced by the directional properties of the light, and how far by successive changes of intensity experienced during the course of their movement. This opens up one side of an intricate problem which has assumed several shapes at one time or another, namely - to state it briefly, if crudely - the question of the relative importance of direction as opposed to change of intensity. It appears to be an appropriate enquiry in the present case, in view of the evident effects of diurnal changes in intensity on the distribution of the wild populations of various plankton organisms. Let us see, then, in what precise ways the problem is applicable to these animals in confined spaces. For simplicity we will restrict considerations to photo-positive behaviour, but they apply equally, mutatis mutandis, to photo-negative.

A. As concerns the group. The collection formed on the lighted side of the vessel may have formed because $(a)$ it is nearest the light-source, or $(b)$ it is in the brightest part of the vessel. It usually happens that movement towards the source is accompanied by increase in intensity, but conditions can be devised in which the two factors are dissociated. In the one case the group should form along the line of incidence of the light, in the other, in a region of maximum illumination irrespective of direction of incidence. Experiments bearing on this point are described below.

B. As concerns the individual. In so far as the group is homogeneous (and in this case it is so to be regarded), a complete interpretation of its behaviour will be given from the study of a typical individual composing it. 
The varieties of individual behaviour that lead directly to the formation of groups in regions of some definite illumination are as follows.

(I) Activity may vary with light intensity, and so the animals may tend to concentrate in that intensity in which the movement is slowest. This is a purely photokinetic effect. Its success in bringing about formation of groups is not great unless very marked differences in activity are produced. Thus (for a negative case) Gonionemus murbachi collects in the shaded part of a tank, partly because of decrease in activity. (YERKES, 1903 ; MURBACH, 1909.)

(II) The direction of movement may still be random, with the exception that reversal reactions are given to abrupt changes of intensity. Thus it is well known that Euglena viridis collects in (not too strongly) lighted regions owing to avoiding reactions when entering a shadow (see JENNINGS, 1906). Similar behaviour is claimed for Bacterium photometricum and various Protista, and probably occurs more than is suspected among Metazoa such as Isopods.* For the appearance of this kind of group it is necessary that there should be an abrupt change from light to shade in the field of illumination.

(III) The animal may exhibit, to a greater or lesser degree, some form of phototaxis. That is to say, the light influences the direction of movement. So long as it is reactive, the animal, as it moves, is constantly making some sort of adjustment in relation to the light, so that the course it follows bears some definable relation to the conditions of illumination. Various forms of phototaxis have been distinguished. They have been classified by KUHN (1919) and reviewed by FRAENKEL (1931). In light of these publications, and of other contributions to the literature of subject, the varieties of phototactic behaviour that we must be prepared to find may be conveniently grouped as follows :-

(a) The animal is capable of at least fairly accurate orientation, in a strict sense, in the direction of incidence of the light. It is not necessary that the animal should be in some way capable of directly appreciating the direction of the light, as, for example, by adjusting the position of a certain transparent tissue to the direction of the light passing through it. Nor is it necessary that the light should directly alter the tonus of the muscles, thus forcing the organs into certain positions, so that the animal is as passive an agent as is a dead body in the way it acts in respect to gravity. It is, indeed, sufficient that the animal can somehow appreciate differences in intensity on the two sides of the body. By nervous response it tends to adjust its course so that bilateral photoreceptors receive equal illumination. One of the first detailed quantitative investigations on

\footnotetext{
* Shock reactions on passage from shadow to light are recorded by Müller (1925) for negative Oniscus.
} 
phototaxis, namely that of PATTEN (1914) on blowfly larvæ, demonstrates this method of orientation. The more clear-cut cases of tropotaxis are included in this category. They appear to be widespread, occurring in various kinds of animals. One might expect that animals with eyes sufficiently developed to discriminate some sort of visual field will be able to orientate more efficiently, displaying less searching movement, than, for example, a blowfly larva, which has no eyes, or a Calanoid Copepod, which has a single median eye.

(b) Orientation may be very inaccurate, and so the path followed irregular, but the animal still be capable of distinguishing differences in intensity on the two sides of the body. The irregularity may be the result either of intermittent sensitivity, or due to the fact that the animal can only appreciate large differences in intensity.

(c) The animal moves in a course directed in the path of the light, not in the above manner, but through response to changes in intensity as its photic-sensory area moves into the shadow of the body. This type of movement was originally ascribed by JENNINGS to Protista, such as Euglena viridis. Though BANCROFT (1913) brings forward good evidence that Jennings' explanation is inadequate for that organism, a genuine case appears to be provided by tadpoles of the Ascidian Amaroucium studied by MAST (1921). In this case the response is not to differences between right and left sides, but to changes in illumination of the photic-sensory area as a whole.

(d) As in (c), the animal is only sensitive to changes in intencity on its sensitive surface as a whole. While it is incapable of any exact orientation, yet, because of the shading effect of the body, the mean direction of its course tends to be in the direction of the light-rays, rather than to the area of maximum illumination (if the latter is dissociated from the former).

(e) As in (d), but the light receptors are such, or the behaviour so adapted, that the intensity changes appreciated by the animal approximate to those that "exist in the physical surroundings." A positive animal will therefore collect in the brightest region, and not at the point nearest the light-source, if these two are dissociated. Though this behaviour undoubtedly takes place with respect to the chemical sense, viz. typical examples of " chemophobotaxis" (e.g. cheese-mite, HENSCHEL, 1929), it is very doubtful whether it is likely ever to occur with respect to light. At one time more than one investigator, using a graded filter, has claimed that certain Crustacea collect in the brightest area and not in the path of incidence of the light, but the experimental conditions seem in no case to exclude other explanations (see p. 424).

These five types may be grouped together in various ways to suit taste or convenience. Thus (a) and (b) are logically grouped apart from (c), (d), and (e), since in the former differences in illumination on the two 
sides of the body are detected, in the latter only differences in total illumination from moment to moment. This seems to be the most rational line of distinction between topotaxis and phobotaxis, though presumably Kuhn's classification would group (c) with (a) and (b) as contrasted with the two others. However, the point is of no consequence for our present purpose, though it serves to illustrate the chimæroid form of biological definitions, according as the emphasis falls on the logical or empirical implications. Or again, in (a) and (c) orientation is in a fairly accurately directed course along the path of incidence of the light; in (b) and (d) the course is irregular about an axis coinciding approximately with the direction of incidence; in (e) there is no connection between direction of movement and direction of light. A grouping of this sort is more appropriate when the cause of aggregations of the animals is the main point at issue.

During examination of the light responses of various plankton animals, an attempt has been made to relate the observed behaviour, by the aid of the above categories, to that of animals that have received more thorough attention, while at the same time to note how far the categories meet the requirements of the species investigated here. It has been considered useful to do this before attempting detailed analysis of the behaviour of any particular species.

Two terms are freely employed in this paper : " phototaxis," meaning that the direction of movement is in some way or another affected by light; and " (photo)topotaxis," a special type of phototaxis in which the direction of movement is controlled by the direction of the light rays. The term "phototropism," formerly used, is avoided, as this has been restricted to the orientation of sessile animals.

\section{METHODS AND MATERIAL.}

In the usual circumstances, such as in the straightforward case of a light-source on a dark background, the light intensity increases in the direction of the source. The two factors are not separated. It is not difficult, however, to devise conditions in which one factor is eliminated, or set against the other. In the case of a parallel beam of light, if loss due to absorption be disregarded, the approach to the source is accompanied by no change of intensity; in a convergent beam, the light intensity diminishes towards the source; in a gradient of light given by a filter increase of intensity* can be opposed to direction; the light source can be made to diminish as the animal moves towards it; both direction and change of total intensity can be eliminated by opposed parallel beams ; while direction is eliminated but change of intensity maintained if a convergent is opposed to an exactly similar divergent beam. If persistently

\footnotetext{
* It should be made clear that the conception of light intensity at a given place means the sum total illumination falling from all directions. The expression is so employed all along. It is referred to as "total intensity" when added emphasis is required.
} 
photosensitive organisms, exhibiting some definite movement in relation to light, are subjected to such varied conditions, an analysis can be made of the light response in question. The external conditions essential for the response will be shown; in particular, it will be possible to estimate the relative importance of direction and change of intensity. Such, in its essence, is the method underlying the experiments of which account is given below.

The various light conditions that were reproduced may be summarised as follows.

(1) Parallel beam. This was procured by means of a wide convergent lens of $20 \mathrm{~cm}$. focal length. Placed against a square glass dish of water, at a distance of $42 \mathrm{~cm}$. from an electric bulb, this lens produced a beam

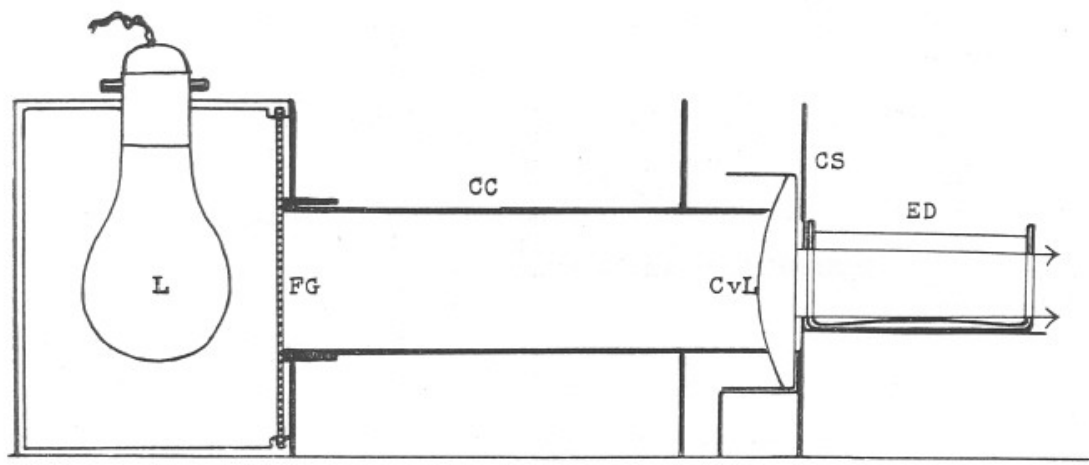

FIG. 1.-Apparatus for procuring parallel beam.

L, daylight bulb, 100 watt. FG, frosted glass screen. CC, cardboard cylinder. CvL, convergent lens. CS, cardboard screen. ED, experimental dish.

which slightly converged from the parallel. The convergence may be regarded as adequate to counteract any loss of intensity due to absorption. The essential details are reproduced in Fig. 1.

It was not found necessary to use a filter for infra-red rays, as over reasonably short periods there was no appreciable change of temperature, and no significant difference was observed in the behaviour of the animals even over long periods. The lens itself must have absorbed a large proportion of these rays. However, if lights were to be kept on for long periods, a battery-jar of water was placed between the light and the lens. The jars shown in Fig. 3 are for this purpose.

On occasions the screen of frosted glass placed close to the lamp was omitted from the apparatus.

(2) Convergent beam. Apart from preliminary experiments in which a cylindrical jar of water was used, a convergent beam was procured by substituting, in the above apparatus, a convergent lens of much greater refracting power (see Fig. $2 \mathrm{a}$ and b, and p. 400).

(3) Convergent opposed by divergent beam. The convergent beam was produced with the same lens as in (2), and passed through a dish $7 \mathrm{~cm}$. 
wide. A divergent beam was obtained from a second light-source on the opposite side of the dish, the correct amount of divergence being secured by means of cardboard screens suitably placed. The intensity of the second light was reduced by a sheet of ground glass (Fig. 3). An adjustable resistance was fitted to the lead of the first light-source, so that the intensities of the beams could, if required, be equalised. A grease-spot on a piece of white paper provided an adequate indicator for the latter purpose.

(4) Light gradient. Methods involving the use of a triangular glass dish. filled with an absorbing liquid, or some kind of screen of graded absorbing capacity, have in the past been employed by investigators desirous of
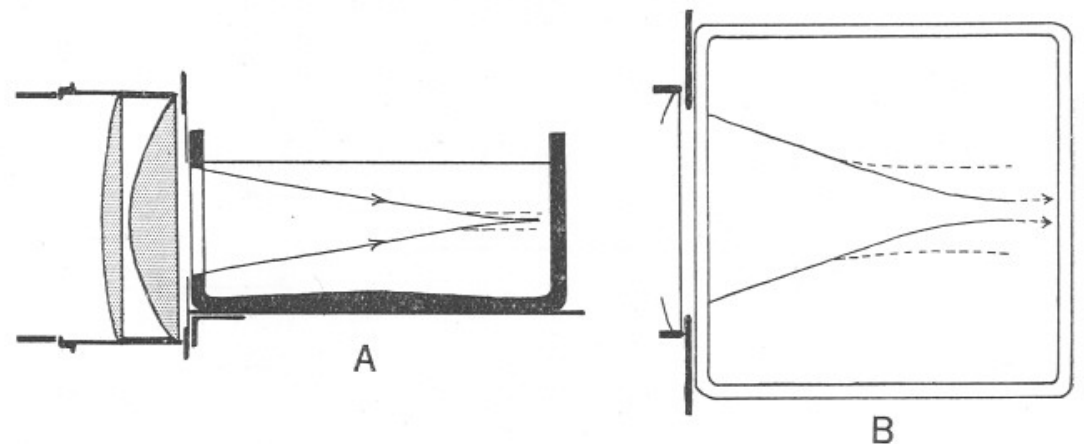

FIG. 2.-Apparatus for procuring convergent beam.

(a) side view of lens and dish.

(b) convergent beam from above.

obtaining an intensity gradient antagonistic to the direction from which the light is coming. The apparatus employed in the experiments here described consisted of a triangular dish filled with an appropriate solution. (Figs. 11, 12, and 13) placed horizontally between the light-source and a long glass dish containing the animals. The latter dish stood on a dark board marked in squares. A screen was fitted around the filter in such a way that no direct light reached the experimental dish from the light-source other than that which passed through it. Suitable precautions were taken to minimise light reflected from the sides of the dish. The triangular dish was filled with either ammonia copper sulphate solution or diluted Indian ink. The one gave a clear passage to the light, of which all that came through except at the extreme bright end was deep blue; the other caused differential scattering of the components of the radiation, so that the light that came through became increasingly red towards the dark end, until only the red outline of the filament showed. The concentration of the solution was so adjusted that an obvious gradient was shown on a plain white surface. In the case of the copper solution, the 
actual concentration was measured. Methylene blue solution was also tried.

Various other lighting conditions were also set up at one time or another, some of which are referred to in this paper. For instance, two parallel beams, procured by a duplication of the apparatus in (1), have been opposed to one another, and the intensity of one, or both, varied by means of an adjustable resistance. Again, two such parallel beams have been placed at right angles to one another. Certain such modifications of the

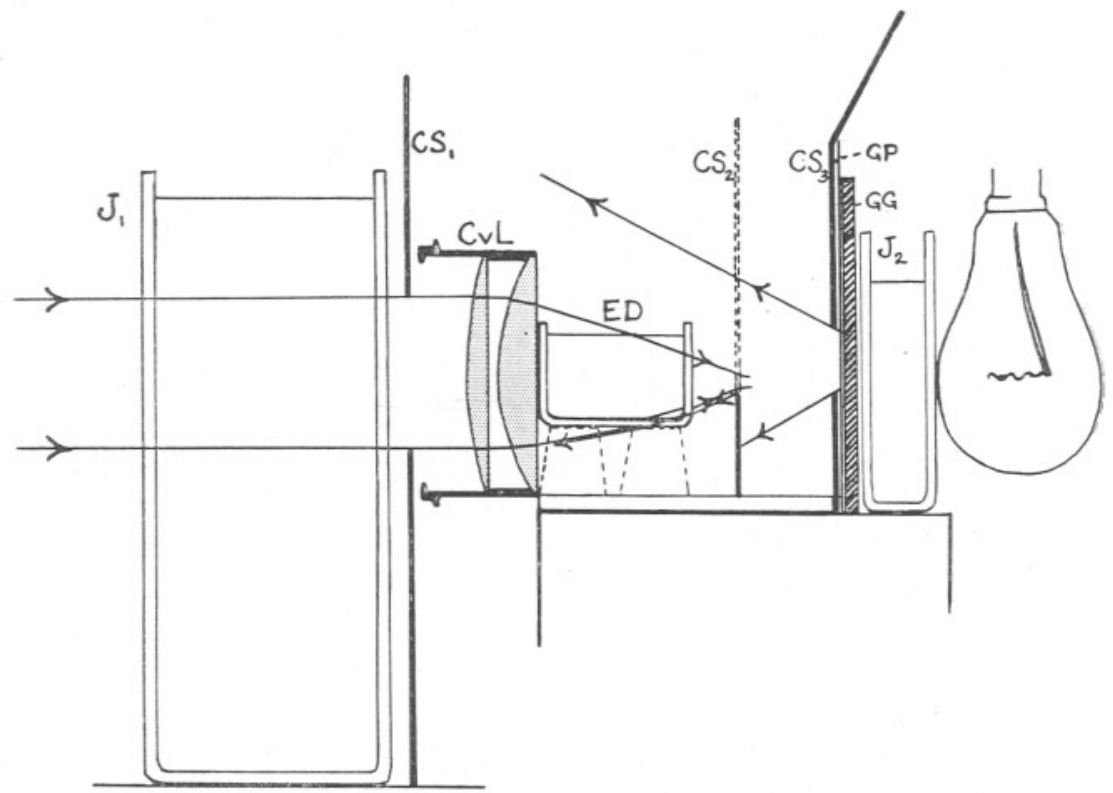

FIG. 3.-Apparatus in which a convergent is opposed by a divergent beam.

J, jars of water. CS, cardboard screens. CvL, convergent lens. ED, experimental dish. GP, sheet of grease-proof paper. GG, sheet of ground glass.

above four main varieties of apparatus employed are mentioned during the course of description of the experiments.

Notes on apparatus. The sources of light consisted of 100 Watt daylight electric bulbs, either Osram or Mazda, gas-filled.

Glass dishes. Rectangular, moulded, dishes of $15 \frac{1}{2} \times 15 \frac{1}{2} \times 7 \mathrm{~cm}$. were most frequently in use. Selection was made of those in which the glass of the sides was most regular. The dish shown in Fig. 11, ete., was $47 \times 12 \times 7$. Use was also made of a special cemented dish, $11 \times 6 \times 15 \frac{1}{2}$, in which the glass was perfectly free from blemishes.

Water. The water in the dishes was always pure "outside" sea-water, which had reached room temperature.

Scattered light. The experiments were carried out in darkened rooms in which extraneous sources of light were negligible, if not entirely absent. The sources of light in the experimental apparatus were always adequately screened. But more difficult to deal with is the light which diffuses from the beams themselves or which is reflected from the sides and corners of the dishes. Precautions to eliminate the effects of such light were taken where necessary, and as far as the experiments go, the results are not complicated 
by such effects. Perhaps, however, one exception to the latter statement is in respect to the light-gradient dish, where light reflected from the back side many to a certain extent assist scattered light in producing a deviation from the path of the direct light (see p. 414).

Preliminary experiments, and such in which apparatus 3 was concerned, were conducted during the spring of 1931 in a cellar. Here the temperature fluctuated little and remained conveniently cool. The room could be darkened completely. In the second part of 1932 the greater part of the work was conducted in another room which provided better facilities. It was darkened for the purpose. The temperature here varied from $22 \cdot 5^{\circ} \mathrm{C}$. in August to $14^{\circ} \mathrm{C}$. in October, but was not subject to large diurnal changes.

The plankton animals investigated were taken from groups of healthy survivors in fresh tow-nettings from the English Channel off Plymouth Sound. They were transferred to dishes of clean sea-water and left for a time to become habituated to the new conditions. As a rule it was then merely a matter of selecting those specimens which were showing persistent aggregation towards, or away from, the lighted side of the dish, or showing any kind of response to light. Their behaviour in one or more of the experimental situations was then recorded, but only in so far as the particular response remained. Specimens which lost activity or became erratic in their behaviour were discarded. Since it was the primary aim to investigate the responses themselves, and not the extent to which any given animal would exhibit them, it was beside the point to consider how the experimental conditions compared with those in nature, or how fluctuations in light intensity or temperature might affect the appearance of a certain response. It was sufficient that the animal continued to show it.

All along care was taken to observe that the animals were consistently exhibiting the response under investigation. In general this presented no difficulty. One of the most likely changes that would have upset results would have been sudden changes from positive to negative behaviour, such as is readily induced in some species, e.g. Temora longicornis. But such behaviour was very infrequent, and quite obvious when it did occur. It may be noted that the light intensities in the dishes were always low, as compared with daylight, and well below the limit that might have induced species living in the upper levels of the water to revert from positive to negative. Again, there may be temporary or intermittent loss of sensitivity to light, so that movement becomes more or less random. But this did not occur under experimental conditions if it was not also observed in ordinary illumination.

The animals were handled as carefully as possible with a fairly widemouthed pipette, and the water in the dish to which they were introduced disturbed as little as possible during the procedure. They could be 
attracted to any required position in the dish with the help of a subsidiary light; so that, once they were in the experimental dish, no further handling as a rule was necessary.

When not crowded, most of the plankton which survive under these conditions generally remained healthy for two or three days, if not more. For the most part, however, those investigated had been captured the previous day.

The names of the species investigated are in all cases those adopted in the Plymouth Marine Fauna, Second Edition (1931).

In identification of specimens I am indebted to Dr. M. V. Lebour and Mr. D. P. Wilson for the help, on various occasions, of their special knowledge. It also gives me pleasure to record my obligations to Dr. E. J. Allen, Dr. W. R. G. Atkins, and Mr. F. S. Russell for helpful criticisms and suggestions.

\section{BEHAVIOUR OF PHOTOPOSITIVE SPECIMENS.}

\section{In Divergent and Parallel Light.}

In proceeding with the account of certain laboratory observations to be described, it is proposed to start with a survey of the various species of plankton animals which have been noticed during the course of the work to give positive movements to light. It was soon clear that animals forming positive groups are very largely, if not always, forms which exhibit some definite phototactic movement. At any rate, among the variety of forms studied, no cases were encountered in which grouping was effected by methods I and II (see p. 388). All light response with which we are here concerned falls under the broad category of phototaxis.

In the ensuing account of the characteristic behaviour of different species, it is implied that the direction of the light is horizontal.

Centropages typicus, a medium-sized species of Copepod, is often persistently attracted to the light. It shows two main types of movement: (a) regular steady swimming, keeping a straight course in the direction of the light; $(b)$ rapid darts, which may be carried over a considerable distance, and in which the course is more or less zigzag. The straight, steady movement is typically interrupted by short pauses, which correspond to the sinking phase of the up-and-down movement observed when the light-source is from above. When orientated horizontally, the animal may have either dorsal or ventral surface uppermost. Indeed the latter position seems to be more frequent than the former. The habit of swimming indiscriminately front or back-side uppermost appears to be quite general among Copepods.

The two above-mentioned types of movement, rapid and slow steady, 
are to be seen in other species of Copepoda. Temora longicornis progresses either rapidly in a zigzag course, as though hurling itself to the light, as well as by slow, steady movement interrupted by pauses. Paracalanus parvus swims a straight steady course, with fewer checks than is usual in Centropages, or else, particularly in a beam of light, may move in quick jerks. Calanus finmarchicus, again, moves either slowly and steadily in a straight line for the source of light, or rapidly, by jerks, in a rather zigzag course.

Another Copepod, the abundant Acartia clausi, behaves in quite a distinctive manner. Its movement to the light, usually rapid, is accomplished by a series of jerks (between which there may be, if movement is slow, a considerable pause), the path followed being somewhat zigzag. The noteworthy feature is that no constant orientation of the body is maintained during this lightward movement. The animal perhaps most frequently assumes a more or less vertical position, the head uppermost, and the dorsal surface facing the light-source; but during the course of movement no one position is kept for any length of time. The animal may come to face in almost any oblique direction : upwards, sideways, diagonally, or even downward. There is therefore no question here of the course of movement being dependent on the direction in which the body is orientated. And further, when the animal remains still there is no orientation; it is only after movement has begun that a lightward direction can be detected.

Corycaeus anglicus, a small species with excessive development of the eye lenses, is spasmodically attracted to light. It moves with fair speed, somewhat jerkily but without pauses, characteristically keeping a straight course. This movement is more vigorous than the slow steady straight movement observed in other Calanoids, but in either case there is constant orientation of the body in the direction of the light rays.

Occasional positive specimens of Anomalocera patersoni have been observed. In this species locomotion is strikingly different from that in other Copepods investigated, being stronger and more deliberate-a difference that is no doubt associated with predatory habits.

Euterpina acutifrons, a Harpacticoid Copepod abundant in fine townettings from the Sound, moves by a rapid succession of short jerks. Though sometimes they keep in a straight path, their course is often erratic, deviating from one side to the other. However, on account of their activity, and because it has been possible to observe numbers at a time, they have given satisfactory results in certain experiments described later.

Males of the parasitic Caligus rapax are, as a rule, photopositive. When swimming with dorsal or ventral side uppermost they move in a straight. line towards the source, the body orientated in the direction of the rays. 
If, however, as often happens when the light is horizontal, they turn and swim on their side, the direction of movement is at an angle to the path of the light, the dorsal side facing the source. At intervals the animal turns over, "tacking " in the opposite direction. As a result, the course followed is zigzag and leads the animals towards the light-source (Fig. 5). In a parallel beam the angle is approximately $45^{\circ}$, the turns being thus made through a right-angle. This instance is evidently to be classed among those light reactions to which the term menotaxis has been applied. It is the only example that has come under notice.

The nauplii of Balanus balanoides progress with the jerky motion characteristic of Crustacean nauplii. The lightwards path is more or less straight, but if a specimen is watched closely a good deal of deviation from side to side may be seen. On account of the persistency of the photopositive movement, these animals provide favourable material for laboratory experiments. The same persistent photopositive tendency was found in the newly hatched nauplii of the freshwater Cheirocephalus diaphanus. A specimen of an unidentified Cirripede metanauplius moved towards a light-source in a straight path.

Among the immature stages of Decapod Crustacea, the planktonic forms seem as a rule to be strongly reactive to light. Mention may first be made of the larvæ (first and second stages) of Galathea squamifera and dispersa. These were found to move straight to the light with their posterior end foremost. In the best performers the body is held accurately orientated, the path taken direct, and the movement continuous. Either ventral or dorsal side may be uppermost.

As in the case of other species capable of accurate orientation, the paths may often undulate considerably-even in a specimen which has only just previously moved in a straight path.

The first larvæ of Upogebia sp. (probably stellata) also orientate and move backwards, and are also capable of swimming in a straight path up a beam, but were found to be more erratic than Galathea. This curious habit of swimming backwards was pointed out by LYON (1906), who found that Palæmonetes larvæ move to light in this way.

The first Zoeas of Carcinus maenas have been found to be strongly photopositive, moving up a beam in a steady, and remarkably straight, course. They orientate in a normal manner, anterior end facing the light and dorsal surface uppermost. The elongate 1st Zoeas of Porcellana sp. (probably platycheles) also react persistently, moving straight forward towards a light-source or up a parallel beam. Owing to their long anterior spine it is easy to observe the exact direction of orientation in these larvæ, and it seems typical for them continuously to sway from side to side as they travel along. But this swaying is through a small angle only, and the mean direction of movement is in a straight line to the light source. 
Specimens were sometimes seen to move backwards, but in this were not in the least handicapped in maintaining a direct path. The abdomen was moved rapidly, and the body swayed from side to side a great deal, but the speed was much the same as in direct forward movement. One specimen, perhaps with a limb hampered in some way, rolled over continuously to the left, and thus progressed in a spiral. And yet it kept a straight course up the beam.

Various other Zoea larvæ of crabs have shown photopositive behaviour, several moving in a straight line towards the source. Some of these swim backwards, the long posterior spine pointing ahead.

In addition, a specimen of a Pandalus montagui larva, which, though not altogether healthy, deserves mention as it remained persistently positive when tested in a parallel beam, went straight to the source with very little tendency to deviate, although — and this is the point emphasised - orientating at various oblique angles.

The larvæ of the herring (Clupea harengus), during the first fortnight of life, show marked tendency to cluster on the lighted side of their tank. Their responsiveness to light appears to be strongest when their activity is greatest. In lowest intensities, not only is there a falling off in activity, but, curiously, a reversal to negative phototaxis. Examination of the movement of individuals in relation to a single light-source, or in a parallel beam, was handicapped by the fact that the intensity was clearly too low. Though all active specimens before long moved up toward the lightsource, they did not steer a straight course towards it and deviated considerably from side to side. After having been kept in the dark for three days their progress up a beam was more definite, but still there was a good deal of random movement.

The young larvæ of a species of goby (Gobiidæ) showed more definite phototactic movement. When active, specimens frequently swam towards the light up a parallel beam, moving in a characteristic way. They progressed by a series of jerks, the direction of each jerk (corresponding to one flick of the tail ?) being different from the one before, alternating to right and left so that the path was decidedly zigzag. The mean direction of the path was, however, straight and coincided with the direction of the incident light (Fig. 8).

Small Polychæt larvæ provide further examples of forms which can be strongly photopositive. They move continuously and directly towards the source, the course taken varying from a straight line to one which undulates regularly. An undulating course is characteristic of a species of Polydora, in which the body is constantly swayed from side to side, so that the head is all the time moving to and fro through a wide arc. A similar type of movement is seen in small free-swimming Turbellarians, single specimens of which have from time to time been under observation, 
In these the path followed deviates irregularly, but an average direction in the axis of the light is maintained. The anterior end of the body is constantly swayed from side to side, suggesting trial and error behaviour. Strong photopositive movement has also been observed in an Autolytid bud carrying eggs, and a Polychæt metatrochophore. In the latter specimen the anterior end moved through a very wide spiral. An unusual example is provided by the Disomid, Poecilochaetus serpens, a young specimen of which was found to be decidedly positive to light and to exhibit quite a unique type of topotaxis. It proved capable of moving straight up a parallel beam, although swimming so vigorously that its movement can only be described by saying the worm threw itself into convulsions.

\footnotetext{
It was placed by pipette at the far end of the beam. At first it lay extended on the bottom; then rhythmic body movements began, which gradually increased in intensity until the worm was, so to speak, coiling on itself. Rising in the water, it swam straight up the beam, coiling vigorously. This procedure was repeated five times with an exactly similar result. Thus, in this example, the path of the animal is direct, whereas no part of the body is orientated to the light. The means whereby the direction of the path is maintained is quite obscure.
}

For completeness it may be added that further instances of observed photopositive movement are provided by Oithona sp. (Copepoda), Sagitta elegans, Mollusca larvæ, and Annelid trochophores. By this time sufficient has been said to show that indisputable phototactic behaviour can be evoked in a wide selection of smaller planktonic animals. This fact remains whatever the extent and significance of such behaviour under natural conditions.

The majority of the above species have been tested in a parallel beam of light (apparatus as in Fig. 1), and in no case was any difference in behaviour observed from that in ordinary divergent light. Since it has been found convenient to use a parallel beam in examination of methods of movement, the data from such tests have been freely included in the above account. Positive movement in a parallel beam has previously been found by ROSE (1925) for Balanus nauplii, etc., and by FRIEDRICH (1931) for Calanus helgolandicus and Corycaeus anglicus.

In reviewing the above account, attention may be drawn to the variety there is to be found in the movements of different positive phototactic forms. Some, such as most Copepods when moving slowly, and Decapod larvæ, are constantly orientated towards the source; others are not orientated to the source although the path followed may be quite straight (Acartia clausi, Poecilochaetus serpens). Some keep the body rigid (Crustacea), others sway the anterior end from side to side (Turbellaria) ; some move jerkily (Euterpina, various nauplii), others smoothly and continuously (Decapod larvæ, Polychæt larvæ). The course followed may be straight (Decapod larvæ, some Polychæt larvæ), zigzag (some Copepods, Sagitta, Gobiid larva), undulating (Polydora sp.), or spiral (Trochophore) ; 
varying regularly (Polychæt larvæ) or irregularly (Euterpina). Several Crustacea swim with either ventral or dorsal side uppermost. It is further to be noted that movement may be to the side (Acartia), or backward (prawn larvæ, Zoeas), or obliquely (specimen of Pandalus larva), and yet a straight course be maintained.

\section{In Convergent Light.}

It has been noted above that photopositive plankton animals will readily move up a parallel beam of light, although in doing so they are not continually passing into light of increasing intensity. Throughout they are subjected to constant illumination. One may next enquire what happens when the beam of light is made to converge, so that movement towards the source necessitates passing from higher to lower light intensities. Accordingly examination was made of the animals' behaviour in a convergent beam.

In the apparatus employed (Fig. 2) a convergent beam passing through a rectangular opening of $8.8 \mathrm{~cm} . \times 4.5 \mathrm{~cm}$, shrank from $7.8 \times 4.2$ (dimensions on entering the water in dish) to $1 \cdot 2 \times 0 \cdot 8 \mathrm{~cm}$. in a distance of $10 \mathrm{~cm}$. When allowance is made for loss of light due to scattering, etc., the increase in intensity over this region was calculated as approximately 25 times.

The results obtained for various species tested are given below. In all cases care was taken that the specimens chosen were reacting positively to ordinary light.

Centropages typicus. On several occasions positive specimens were placed in a convergent beam, always with the same result. Provided they did not stay motionless, they moved up the beam towards the source, and showed no tendency to stay in the brightest region. In short, they reacted just in the same way as to divergent or parallel light, thus showing the importance of the direction of incidence as against change of intensity. Notes on the behaviour of 24 adult specimens are shown in Table I. Moreover, their average courses followed the paths of the light-rays; that is to say, starting in the brightest region the paths taken spread out in a fan coinciding with the direction of the converging light. In nearly all cases the animal kept at the edge of the beam, either at the side, or above, or on top. When left undisturbed, the animals congregated against the area of entry of the light (PQ, Fig. 4), where again they exhibited a tendency to collect at the edges. Movement was either very slow, steady, and straight; or more rapid, steady, continuous ; or in rapid jerks.

Specimens placed carefully by pipette in one of the far corners of the dish (19-viii-32) behaved as expected if supposed to follow the course of the light-rays or the maximum diffuse light. The tracks of nine individuals are shown in Fig. 7. 


\section{TABLE I.}

\section{Centropages typicus.}

\section{Notes on movement up a convergent beam of 24 adult specimens (including 10 ธิธิ and 14 우).}

The apparatus is that described on p. 391. (For the first 12 specimens the opaque glass filter was present, for the rest it was absent ; but this does not affect results.) Specimens were placed singly by pipette in the narrowest part of the beam. Unless stated to the contrary, all were photopositive, moving up to the light source. The point at which movement started is recorded : 1.p. $\longrightarrow$ on leaving pipette, e.b. - on entering beam, t.b.on touching bottom.

$\begin{array}{cc}\text { Specimen. } & \begin{array}{r}\text { Started } \\ \text { to move. }\end{array} \\ \text { (with opaque glass filte } & \\ 1 . & \\ 2 . & \text { t.p. } \\ 3 . & \text { l.p. } \\ 4 . & \text { l.p. } \\ 5 . & \text { l.p. } \\ 6 . & \text { l.p. } \\ 7 . & \text { l.p. } \\ 8 . & 1 . p . \\ 9 . & \text { l.p. } \\ 10 . & \text { l.p. } \\ 11 . & \text { l.p. } \\ 12 . & \text { t.b. }\end{array}$

(without opaque glass filter)

\section{slow, with some hesitation}

continuous slow steady

paused, then continuous slow steady

swooping movement, then slow

slow steady

slow steady

slow steady

slow steady

slow steady

slow steady

movement at first irregular started on bottom, swam up and across beam, then hesitated; then swam slowly and steadily to light

$\begin{array}{ll}13 . & \text { l.p. } \\ 14 . & \text { l.p. } \\ 15 . & \text { t.b. } \\ 16 . & \text { l.p. } \\ 17 . & \text { l.p. }\end{array}$

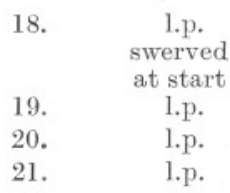

22. e.b.

23.

24.

\section{rapid, then slow}

slow steady

slow steady

swoop, then slow steady

2 or 3 rapid darts, then zigzag, then slow up side edge, gradually carried away from beam; checked, recovered, swam along edge of beam to source

slow steady

slow steady

(paused, fell through beam, only giving very slight jerks on coming in contact with the beam. Fell to bottom, from which it moved a little later)

(started positive on side of beam, but tended to move in a circle, and was carried into darker part of dish)

$\begin{array}{ll}\text { l.p. } & \text { rapid } \\ \text { l.p. } & \text { slow steady }\end{array}$
Position of path.

side edge of beam. lower edge, in centre. side edge. side edge. inside beam. side edge. centre, top edge. centre, top edge. centre, top edge. centre, lower edge. centre, top edge side edge.

centre, top edge. centre, top edge. lower edge. side edge.

top edge.

top edge. top edge.

centre, top edge. centre, top edge. 
When the convergent beam was reflected back on itself by a mirror, so that the directive quality of the light must have been counteracted to a large extent, it was found that the Centropages still swam towards the main source. Evidently the intensity of the direct beam exceeded that of the reflected light enough for the excess to be detectable by the animals. This affords an example of an effect which was observed on several occasions-when light is coming from various directions, the animal moves in the direction from which the light is relatively strongest.

Acartia clausi. In this species again no difference of behaviour was detected in divergent and convergent light. In the latter case animals moved towards the light as readily as in the former. Specimens were tested on several occasions, embracing both adults and immature, winter broods, spring broods, and late summer broods. Both slow and rapid movement were observed, as well as the characteristic lack of orientation. When collected at the light-source they showed a marked tendency to select the outer edges of the beam (as in the case of Balanus larvæ, Fig. 9).

Temora longicornis. Positive specimens of this species, again, were found to move up a convergent beam. Several tested (15-vii-32) moved for the most part with rapidity in a zigzag course (though slow, steady movement was also observed); and showed decided tendency to keep to the outer part of the beam, both during movement and when left to congregate.

On another occasion ( $21-\mathrm{v}-31)$ several specimens had been tested alternately in convergent and divergent light of equal intensities in the apparatus figured on page 393. Each specimen was kept on the move for some while by the switching over from one light to the other. On the whole the animals moved distinctly faster up the divergent than up the convergent beam, as indicated below.

Divergent.

Specimen 1. Rapid, rather zigzag.

,. 2. Rapid.

,, 3. Very rapid.

, 4. Rapid, with slight exception.

, 5. Rapid and slow.

," 6. Rapid.

," 7. Partly rapid, partly slow.
Convergent.

Slow steady.

Partly slow, partly rapid. Rapid.

Slow, interspersed with rapid. Relatively slower.

Slow, except at end of path. Less rapid, more slow.

It is not known, however, if any significance is to be attached to this difference. Movement up the convergent beam was, as usual, in the direction of the light-rays, i.e. the paths radiated outwards from the narrow end of the beam.

Euterpina acutifrons. Specimens which moved in a direct line for the light likewise moved directly up a convergent beam. The immature and nauplii also moved up the beam as readily as to an ordinary source.

Calanus finmarchicus. Positive specimens were found to swim to the 


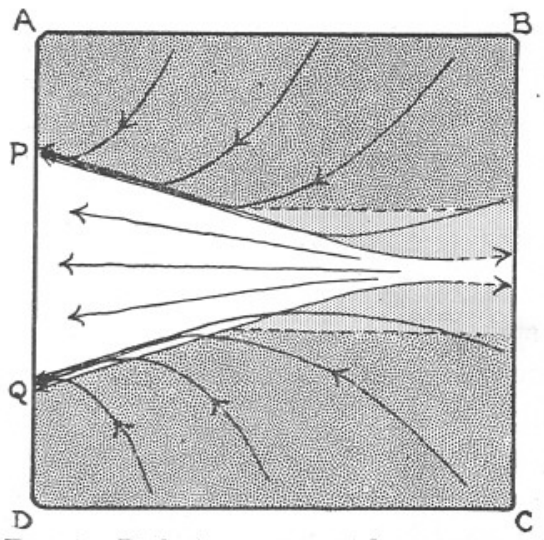

FIG. 4.-Paths in convergent beam-mean direction of those animals which move in the direction of the rays.

$\mathrm{ABCD}$, square dish. $\mathrm{PQ}$, entrance of convergent beam.

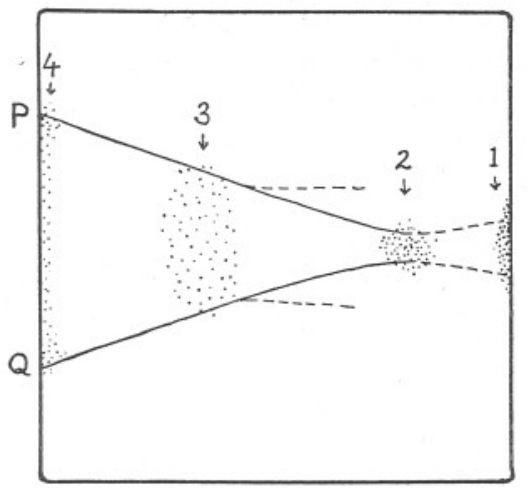

FIG. 6.-Balanus balanoides day-old nauplii - four successive positions ( 1 to 4 ) in movement up a convergent beam. PQ, entrance of beam.

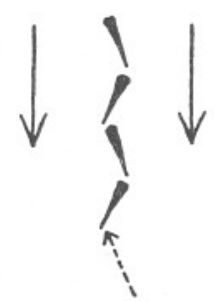

FIG. 8.-Path of Gobiid larva, showing successive positions of the body.

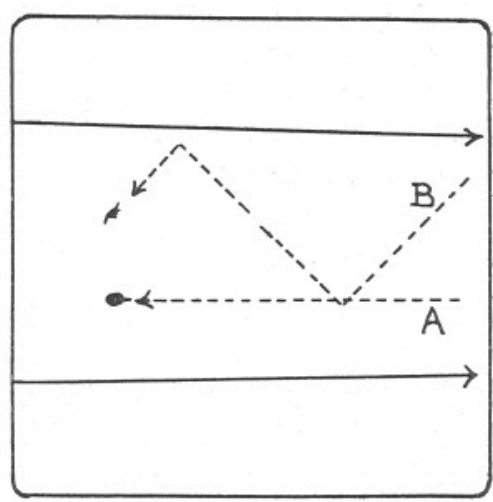

FIG. 5.-Caligus rapax ô-paths in lateral parallel beam.

A, dorsal or central surface uppermost. $\mathrm{B}$, one of the sides uppermost.

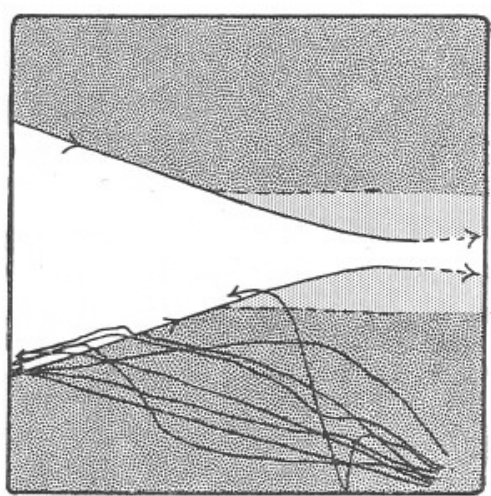

Frg. 7.-Centropages typicus-paths of 8 specimens in diffuse light coming from convergent beam.

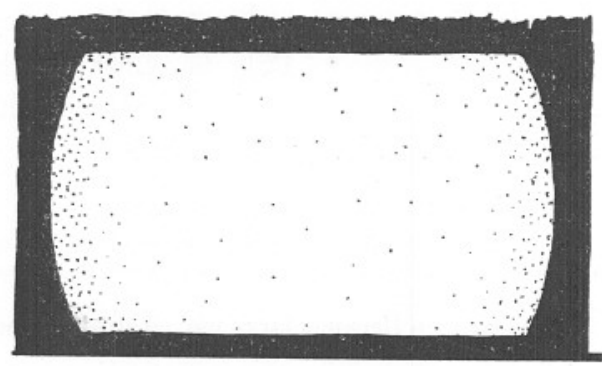

FrG. 9.-Balanus balanoides day-old naupliicongregation at entrance of convergent beam. 
light by steady continuous motion, following the direction of the rays. The tracks in the beam approached the ideal shown in Fig. 4. It may be added that positive specimens have also been found to continue lightward movement when the source was steadily dimmed during the time they were travelling towards it.

Balanus balanoides nauplii. A group of day-old larvæ, strongly positive, gave very clear results in a convergent beam (27-vii-32). They moved up the beam towards the light, the group spreading out in the beam, but not passing outside it. (The region outside the beam could be explored by the light reflected from a mirror.) Four successive positions of the main body are shown in Fig. 6. Within $2 \frac{1}{2}$ minutes from the switching on of the light they had moved from position (I) and congregated against the glass at the entrance of the beam. When collected in this way they tended to accumulate at the edges of the lighted area (Fig. 9), an effect which has been observed in various other species. When the beam is reflected back by a mirror, the larvæ still move towards the direct source, though considerably more slowly and in a more irregular course.

Zoea larva. Zoea larvæ that have been tested in a convergent beam have been found to move as straight and quickly towards the light as to an ordinary source. As in other forms, they follow the direction of the rays. Their paths conform closely with the idealised paths shown in Fig. 4.

Other positive animals which definitely swam towards the source in a convergent beam, thus behaving in a manner comparable with the species described above, include the following :-

$\begin{array}{ll}\text { CRUSTACEA } & \text { Corycaeus anglicus } \\ & \text { Paracalanus parvus } \\ & \text { Oithona sp. } \\ & \text { Caligus rapax ô } \\ & \text { Nauplius of Cheirocsphalus diaphanus (freshwater) } \\ & \text { Podon intermedius } \\ \text { CHETOGNATHA } & \text { Sagitta sp. } \\ \text { ANNELIDA } & \text { small Spionid larvae } \\ & \text { Polychæt metatrochophore } \\ \text { PLATYHELMIA } & \text { small Turbellarian }\end{array}$

To these may be added the following :-

An elongate Copepod nauplius, whose forward movement was regularly interspersed with pauses, remained positive in a convergent beam, the pauses being distinctly longer and more frequent.

An unidentified Decapod larva moved straight backwards up the beam in the same way as it moved to other light sources.

Very small cerearia larvæ from Littorina littorea* were found to collect gradually towards

* I have to thank Miss M. Rothschild for these specimens. 
the light. When a convergent beam was thrown through the beaker containing them, the larvæ gradually collected as before. For considerable periods the larvæ were seen to hang motionless in the water, but every now and then a sudden dart for a short distance was made in the direction from which the light was coming.

Among the various animals tested all gave comparable results, namely positive specimens move up a convergent beam as to any other source of light. There was not a single exception found. This uniform result is all the more striking, as a variety of types were investigated, representing several phyla, and exhibiting a variety of modes of progress (see p. 399).

There were no discrepancies from the general rule that, in so far as the animal normally moves straight in the direction of the light, so, in the convergent beam, its possible paths follow the fan-shaped arrangement of the conventionalised light-rays (as shown in Fig. 4). There was also shown a decided tendency to keep to the outer side of the beam rather than in the centre, and for collections to concentrate most on the outer edges of the beam at its point of entry ; probably to be explained on the grounds that the light was somewhat more concentrated at the edge of the beam.

The results, therefore, emphasise the primary importance of directional properties of the light in photopositive movement of the type ${ }^{*}$ considered. Not only is the increase of intensity which usually happens to be associated with the approach to a light-source unessential, but an appreciable decrease (such as produced by a convergent beam) does not affect the result.

\section{In Convergent opposed By Divergent Light.}

With a parallel beam of light, change of intensity in the physical environment is eliminated while direction is maintained. Direction, too, may be eliminated by opposing two beams of exactly equal strength. If it is required to preserve the change of intensity, it is only necessary that one of the beams should be convergent and the other divergent. Thus a convergent beam exactly opposed by a divergent of corresponding intensity gives a condition in which intensity change is preserved but direction, in one plane, eliminated.

As figured on p. 393 (Fig. 3), a convergent beam, produced as before, was passed through a dish $7 \mathrm{~cm}$. across, and a direct light-source was opposed to it, screened with opaque glass and cardboard slits in such a way that a divergent beam was produced coinciding in position with the convergent. An adjustable resistance (a pair of triangular copper plates which could be moved up and down in a battery-jar of water) was connected with the second light, so that the intensity of the divergent beam could be adjusted to that of the other. A grease-spot, made by a small drop of medicinal paraffin on white paper, provided an effective indicator.

The animals investigated were placed in the glass dish and their positive behaviour checked by switching on one or other of the lights. Throughout 
the course of the experiment it was possible to check the persistence of this behaviour in the same way. It has to be acknowledged that the double-sourced beam was of twice the intensity of one light alone, but the behaviour with which we are here concerned was clearly not influenced on this account. Doubling the intensity of a single light-source was found, on occasions when tested, in no way to desensitise or otherwise to alter the general phototropic movement of the animal.

Acartia clausi. Tested on several occasions, this strongly photopositive species was found to lose orientation altogether in the doublesourced beam. The movement of individuals appeared to be quite random, the jerks being made in any direction. When several were left in the beam, they distributed themselves at random through it.

Euterpina acutifrons is also quite disorientated. Specimens were

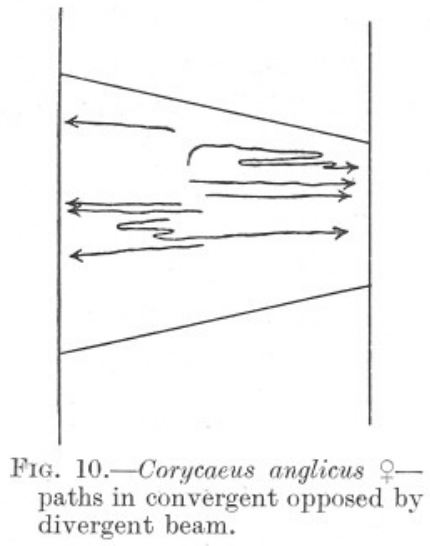

observed to move to and fro in various directions as well as round in circles. As soon, however, as one light was dimmed (an opaque glass filter being interposed), a drifting away from the dimmed source was at once apparent, divergent and convergent source being treated alike.

Contrasting strongly with the above two species, Corycaeus anglicus keeps strictly orientated to one or other of the two light-sources. Positive (or, for that matter, negative) specimens move to and fro in the beam, always in the axis of the light. Fig. 10 is typical of results obtained. This shows the paths taken by a $q$ which was placed by pipette 8 times in the centre of the beam. It travelled straight towards one or other of the lights, and on occasions when it changed direction a complete turn through $180^{\circ}$ was made. As far as tests with this species went, no preference for one or other of the lights was noticeable.

Centropages typicus, again, retains orientation along the path of the light rays, moving without preference to either source. The characteristic behaviour of actively positive specimens is movement from one side 
to the other along the length of the beam with longer or shorter intervals spent at either source. As a typical illustration may be cited the behaviour of an active 9 (20-1-31) on being placed in the centre of the beam 35 times in succession.

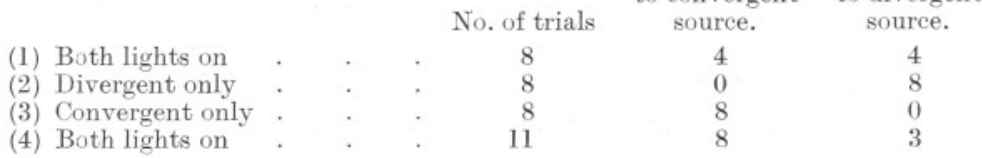

On arriving at the side of the dish it either remained for some time at the light or else soon turned and swam to the opposite source.

Precisely the same sort of behaviour was found with specimens placed in opposed parallel beams-they oriented to one source or the other. With a parallel beam reflected on itself, either the direct source or the reflection can act as a source of attraction.

Temora longicornis, as Centropages, orientates its course in a very noticeable manner to one or other of the sources. Individuals were observed to move to and fro in the beam from one source to the other.

\footnotetext{
A particularly clear-cut instance is that of a specimen which, after being placed in the beam and left undisturbed, swam alternately from one end of the beam to the other. Watched for 2 or 3 minutes, it was seen to move to one source, swim against the glass for a little, then turn and swim straight to the opposite source. During this whole period it made no fewer than 18 journeys, 9 times to each source. Then, for a period of half a minute, the single lights were tried in turn, and the positive behaviour of the animal verified. After this, both lights were again switched on together, and for another two minutes the to-and-fro course was continued. Again, in the same way, 18 journeys were made.
}

Zoea larvo of an unidentified species were tested on one occasion. A number of specimens were watched, and the characteristic behaviour found to be as follows. To either divergent or convergent source alone they move fairly straight and quickly; when both lights are on they are to a large extent disoriented: they move in various directions, but apparently oftener up and down the beam than across. Thus, because their movements are not altogether random, but more frequently towards one or other of the sources, they are intermediate between Centropages and Acartia.

Some of the smaller planktonic forms appeared, like Acartia, to be disoriented in the double-sourced beam. Among these are: Balanus nauplii, Paracalanus parvus, and Oithona sp. It may be added that Podon intermedius and larvæ of Polydora sp. lost orientation in a doublesourced parallel beam, moving in circles.

No other species were investigated, and no further examples can be given of behaviour like that shown by Corycæus, Centropages, and Temora. It is probable, however, that prawn larvæ of various kinds would be found to act in the same way. A specimen of the larva of 
Pandalus montagui was found to steer straight to one or other end of a double-sourced parallel beam.

There was no tendency found, among species investigated, to collect in the brighter part of the beam (divergent source), but it cannot be claimed that the experiments were sufficient to exclude absolutely the possibility of this occurring. At any rate, it is certain that this does not happen in the case of Acartia clausi, specimens of which species distribute themselves at random through the beam. With Acartia, then, we have definite evidence from this source that photopositive movement depends on the directional properties of the light, and not on the change of intensity encountered in passage through the beam. Again, with species which maintained orientation and moved to one source or the other, on no occasion was there any indication of preference for either one of the lights.

These experiments go far enough to bring out two points. In the first place, there is the fact that, in a double-sourced beam, two quite distinct types of behaviour occur. Some species, on the one hand, lose orientation and move about in any direction; some, on the other hand, still orientate to either source. It may be supposed that this difference between these two groups of species results from differences in the light receptors. If the latter structure is affected by the light from all directions more or less equally, then light from two opposed directions may be expected to upset orientation. If, however, the receptor is affected, say, from one direction only, so that when facing that quarter it is screened from the light behind, then orientation to each source in turn is possible. It can be understood that, among various forms of lower animals, some might be affected by light coming from almost any direction, while others might show decided differential selection, being, for example, more receptive to light coming from in front than from the sides, and from the sides more than from behind. Among the former might be included the more transparent and the smaller forms with a single median eye ; among the latter, forms with larger paired eyes with a definitely restricted field of view, forms with a single median eye whose field is reduced by the opacity of the body, or owing to the presence of pigment, forms with well-developed lenses which concentrate light from one direction at the expense of others, or with any other characteristic which may induce inequality in the optical field. This supposition receives support from results given by the species which have been investigated. Those that are disoriented include (i) small transparent forms with a single median eye, such as Balanus nauplii, Euterpina, and Paracalanus parvus, and (ii) the larger, but transparent, Acartia clausi, which, as noted above, does not maintain orientation in any fixed direction when on the move, and so would come under the influence of both lights equally. Those that still 
orientate themselves are species which happen both normally to move straight in the axis of the beam, following the path of the rays, their body orientated towards the light-source, and, at the same time, to give reason to suppose that their eye is wholly or partly screened from the light falling posteriorly. Temora longicornis, though rather small, is pigmented; Centropages is by no means transparent and of considerable size ; while Corycæus possesses a pair of prominent lenses which concentrate the light. from one direction at a time.

The second point to be brought out is that those species which move to and fro to one or other of the sources are evidently still sensitive to the direction of the light. They will continue, moreover, swimming up a convergent beam even though there is divergent light from the opposite: direction.

\section{In a Light Gradient crossing the Path of the Light.}

By means of the apparatus described above (p. 392) it is possible to produce a gradation of intensity from one end to the other of an elongated glass dish or glass tube, in such a way that the brightest end is furthest from the light-source, and the passage in the direction of the light involves. passing into decreasing intensity. Two phases can be observed in the behaviour of the animals studied: (i) the direction of their path across. the dish, (ii) the area in which they congregate when left undisturbed for an adequate period.

(i) When an animal is introduced somewhere along the length of the side away from the light-source, it first crosses the dish, until in contact with the glass of the side facing the source. The course followed may be compared with the known direction of the light and any possible effect of intensity difference noted.

(ii) Assuming that it remains active after coming in contact with the side of the glass facing the light-source, the animal will continuously swim against the glass in the effort of continuing lightward movement. In the ordinary way, that is, if there is no light filter, the result of its movements will be to bring it gradually to the region immediately opposite the light-source, where random variations in direction will be made equally to the right or the left. The animal will, in effect, work its way along the edge of the glass by degrees, until in the region nearest the light-source. A group of animals left to themselves will gradually collect and concentrate in this region. Now, in the ordinary way, the animal is all the time moving into increasing light intensity; whereas when a graded filter is used, the intensity decreases as the region opposite the source is approached. Where, it may be asked, will the animals collect in the latter case? If the region of highest intensity is chosen, they will collect at the end of the 
dish furthest from the source; if influenced by the direction of the lig alone, they will collect opposite the source.

Centropages typicus. The first trials were made with comparativel. highly diluted Indian ink in the filter. The apparatus is shown in Fig. 11 Individual animals were placed by pipette in the region of the dish

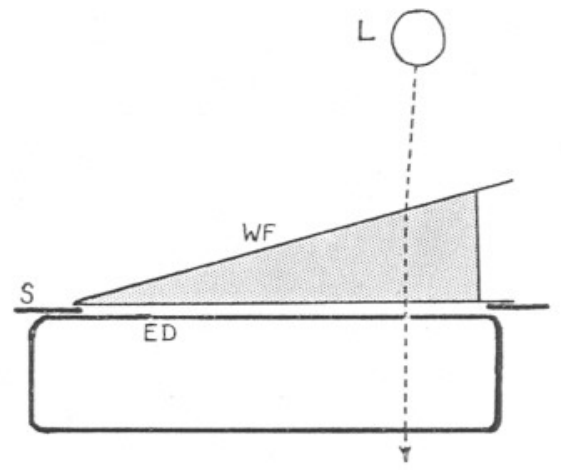

FIG. 11.-Light gradient apparatus.

L, daylight bulb, 100 watt. WF, filter. $\mathrm{S}$, screen. ED, experimental dish.

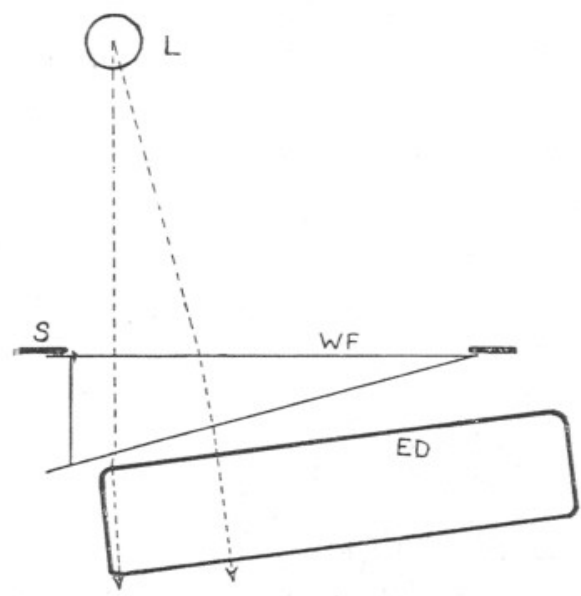

FIG. 12.-Light gradient apparatus. Lettering as in Fig. 11.

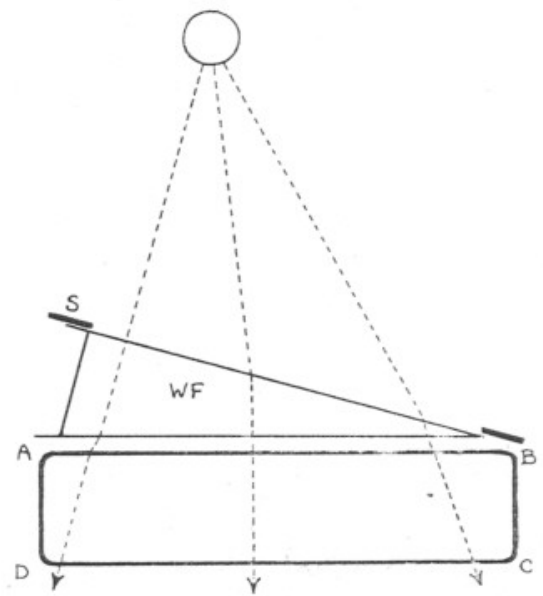

FIG. 13.-Light gradient apparatus. Lettering as in Fig. 11. Corners of experimental dish marked ABCD.

furthest from the source and their subsequent movement noted. The paths of the 25 specimens tested are shown in Figs. 14A and B. It will be seen that the paths coincide closely with the direction of the light-rays. No marked deviation towards the brighter region (i.e. in the direction of $\mathrm{Z}$ ) can be detected. Furthermore, the animals did not take long to work 
up the dish to the region opposite the light, where they then collected. This behaviour-moving in path of the light-rays and collecting at the point nearest the source-is what is to be expected of animals whose photopositive movement is regulated by the direction of the light rather than by change of intensity.

When, however, the strength of the Indian ink solution was increased, so that a more pronounced gradient was procured, and very little light penetrated direct into the darker end, the paths of specimens tested (this time liberated in middle region of the dish) showed a noticeable deviation to the left, that is, towards the brighter part of the gradient.

This deviation was then demonstrated more accurately. The same solution of ink was used, and the apparatus arranged as in Fig. 13.

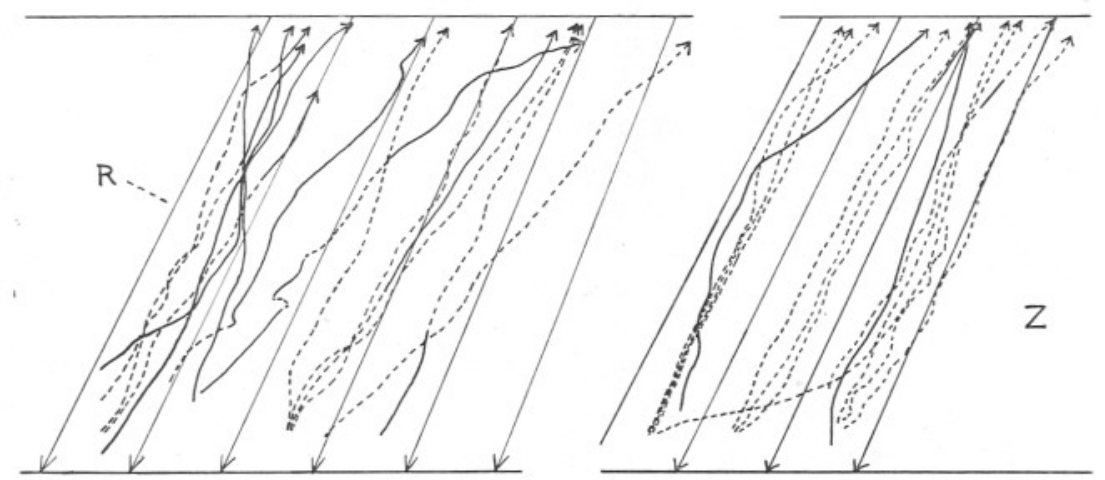

A

B

FIG. 14, A and B. Centropages typicus-paths in light gradient.

$\mathrm{R}$, arrows indicating direction of the light.

$\mathrm{Z}$, direction of brighter end of gradient.

Twenty-five specimens were released immediately opposite the point of direct incidence of the light. Note was taken of the point at which they arrived at the opposite side.

The distance of the direct path was $11 \mathrm{~cm}$. A dark board underneath the dish was marked in 2 -cm. squares, the scale being expressed in cm., 0 to 46 . In this case the point opposite the source, where the light fell at right angles to the dish, was at 25 . The points of arrival were grouped in $2 \mathrm{~cm}$. lengthe.

It became clear that the animals deviate slightly towards the brighter end of the dish (i.e. in this case to the right), as the results given in Table II show. There was, in fact, an average deviation of $1 \cdot 2 \mathrm{~cm}$. to the right over the direct course of $11 \mathrm{~cm}$. The next day the experiment was repeated, the same batch of animals being used, with similar results, shown in the same table. No record of the actual tracks was kept, but it was most noticeable that such deviation as was apparent occurred mainly in the last 
4 or $5 \mathrm{~cm}$. of the path. An estimated mean path is shown in Fig. 16. That a deviation should be found is not surprising; the cause of it is discussed below. In the majority of animals the movement was slow, and at the same time jerky.

TABLE II.

Paths of Centropages typicus across Light Gradient.

Point of

Animals released at $\mathbf{2 5}$.

arrival along $\mathrm{AB} \quad 20-22 \quad 22-24 \quad 24-26 \quad 26-28 \quad 28-30 \quad$ Average deviation.

Number of specimens

$\begin{array}{rrrrrrr}12-\mathrm{x}-32 & 0 & 3 & y & 12 & 3 & 1 \cdot 2 \text { to Right }(25 \text { to } 26 \cdot 2) \\ 13-\mathrm{x}-32 & 0 & 1 & 10 & 11 & 3 & 1 \cdot 3 \text { to Right }(25 \text { to } 26 \cdot 3)\end{array}$

Note.-In each series the same animal may have been used on more than one occasion. Very few gave no results, i.e. remain inactive.

When some Centropages were left in the dish, they did not concentrate exactly opposite the light-source (at 25), but kept distinctly to the right. This behaviour was also shown, and more obviously, by a number of Acartia in the dish at the same time.

It is not difficult to account for the occurrence of this deviation from the path of the direct light; for it is clear that, if body-orientation in some way depends on a balance of the light falling on the two sides of the animal's body, excess of diffuse light on one side will cause a deviation of orientation in that direction. In the darker part of the dish the amount of diffuse light coming from the brighter end must have a strength of an order comparable with that of the direct light, and so introduce an appreciable lateral component into the light effective in regulating the animal's course. The excess of diffuse light on one side will also influence the position round which the animals tend to congregate-for at the point nearest the source random movement will now tend towards the brighter side rather than the other. This question is fully treated later, after some experiments with Euterpina have been described.

Euterpina acutifrons. In a preliminary test, with the filter arranged as in Fig. 11, and containing methylene blue solution, it was noted that immature animals moved obliquely across the dish more or less in the direction of the rays and steadily accumulated at the dimmer end of the dish round a point almost opposite the light source. As in Centropages, the brighter end was ignored.

With diluted Indian ink in the filter, it was observed that now, on the whole, the paths of adults and immatures, moving across the dish at the brighter end, noticeably deviated to the left. Then, when left to congregate, the animals were found concentrated in an area opposite the lightsource - or somewhere to the left of it. 
When the filter, filled with half-strength ammonia copper sulphate solution, was arranged as in Fig. 18 (except that the dish was placed parallel with the lighted side of the filter, so that the point nearest the source was at the extreme left end), adults, immatures, and nauplii aggregated quite rapidly to the left side of the dish opposite the source of light. The paths of individuals, judging from the way a group expanded from the point at which introduced, on the average appeared to approximate well with the path of the light rays. The behaviour was no different

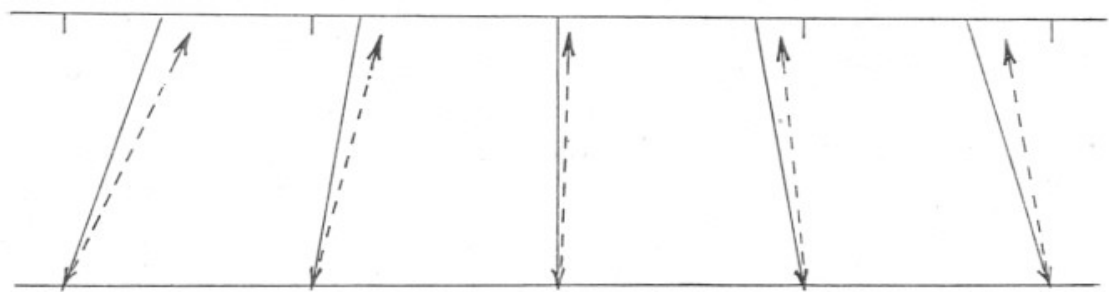

FIG. 15.-Balanus nauplii-paths in light gradient. Continuous line, path of direct light; broken line, path of larvæ.

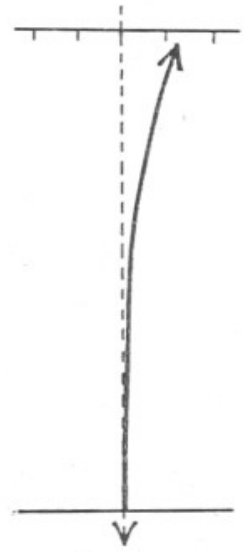

Fig. 16.

Centropages typicus mean direction of path across light gradient.

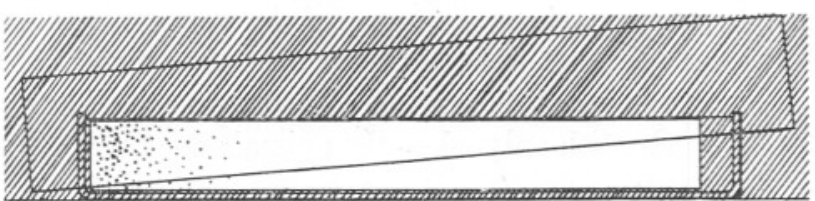

FIG. 17.-Euterpina acutifrons in light gradient (see text).

when a length of opaque glass was stood between the filter and the dish. The animals even continued to congregate at the left-hand end (1 to 18) when the opaque glass was stood obliquely, as shown in Fig. 17, in a way which greatly accentuated the gradient. Further, when the apparatus was arranged as in Fig. 13, the animals congregated in the neighbourhood of 25 ; and again when it was arranged as in Fig. 12, they collected about 18 , that is, once more approximately opposite the light-source. With 
this filter, therefore, there was shown no marked deviation from the path of the direct light; though it should be added that the average paths of individuals placed in the dark end (at 5) or opposite the light (2) seemed consistently to show a slight trend to the right of the order of $1 \mathrm{~cm}$.

By contrast, a very noticeable deviation towards the brighter end was found when Indian ink was placed in the filter. Six different mixtures of increasing concentration were tried in turn. No. 1 mixture was just strong enough to give a perceptible gradient; while no. 6 so dense that the filament of the electric bulb was only just visible in the darkness of the left-hand end of the dish, and it was only the right-hand third of the dish that received any appreciable illumination. No. 2 was twice the concentration of 1,3 twice that of 2 , while 4 and 5 were intermediate between 3 and 6 . In each case a group of Euterpina were given adequate time to form a cluster opposite the light, and the position of the midpoint of the cluster was recorded. In each case, also, active specimens were introduced opposite the light-source and the trend of their movement observed. The results, which are graphically shown in Fig. 18, A to F, are as follows :-

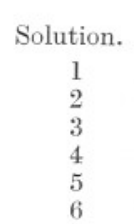

Midpoint of
photopositive cluster.
27
28
30
31
37
39

Deviation to
right.
2
3
5
6
12
14

The figures also show the trend of the paths of specimens traversing the dish. In all cases, when starting from 25 , they veer towards the point at which the group is formed. The mean path is at right angles to the length of the dish only when the animals are liberated opposite the centre of the group.

The point clearly brought out is that, as the thickness of the filter increases, so the direction of the animals' movement deviates increasingly from the path of the direct light, until a stage is reached at which the animals are, so to speak, driven far into the brighter end of the dish.

It should be pointed out that there is no question of the animals becoming negative to light in the lower intensities. Some tests were made with the same animals used in this experiment and it was found that the animals remained sensitive to light of very low intensity, reacting positively all the time. Moreover, any possibility of the animals having become negative or desensitised during the experiment is entirely annulled from the fact that the animals continued to cluster on the side of the vessel facing the source. Negative animals would have grouped on the opposite side, while desensitised animals would not have formed clusters at all.

It is noteworthy that even in the condition shown in Fig. 18F, the 
brighter (right-hand) corner is avoided by the animals. The group does not extend into it. By this fact we are assured that the animals are still not grouping in the region of highest light-intensity as such, any more than in other cases.

In respect to the light conditions to which the animals in the dish were
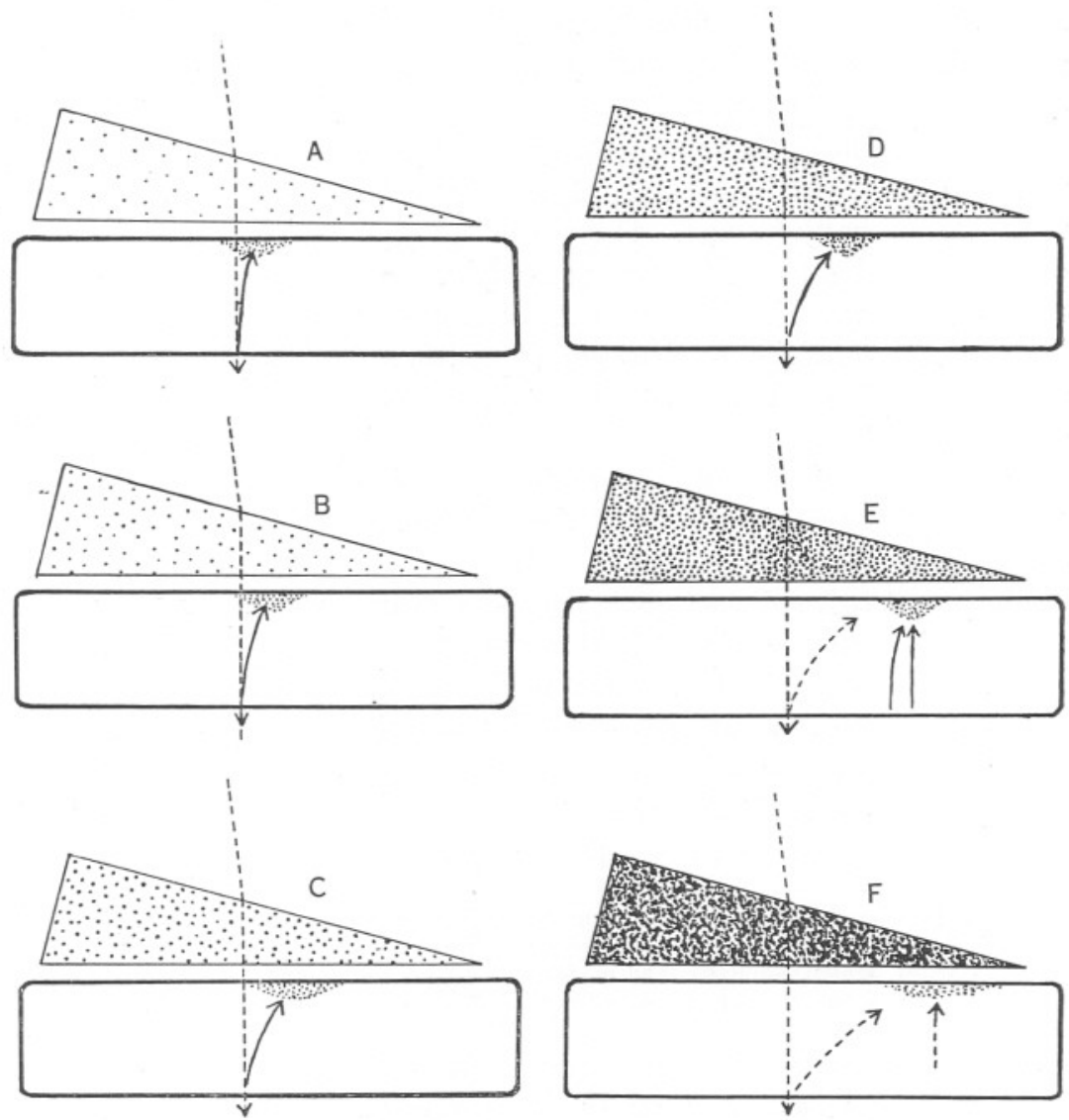

FIG. 18, A to F. Euterpina acutifrons - mean paths and groupings in light gradient with increasing concentration of filter.

subject, it is important to emphasise that the ink suspension in the filter has a considerable scattering effect on the light, thus increasing the amount of diffuse light at the expense of the direct. One would therefore expect the paths of the animals to show more deviation with Indian ink in the filter, than with a clear solution such as ammonia copper sulphate. The deviation would necessarily become greater as the thickness of the solution increases. A further point is that the filtered light becomes 
increasingly redder the more it is absorbed: it gets more and more reddish from the brighter end of the gradient to the dark. Since the Euterpina are presumably less sensitive to this than other parts of the spectrum (some experimental evidence on this was obtained), the gradient will, if anything, be accentuated from their point of view: And such accentuation would tend to increase the deviation of their paths.

After the above considerations it is sufficiently clear that the cause of the deviation is the excess of diffuse light coming from the right-hand side of the dish. In Fig. 18F, it is particularly obvious that an animal, moving in a path in which illumination on its two sides is balanced, if starting in the middle, will move diagonally across the dish towards the region where the group actually formed. There is no question here of the significance of the diffuse light coming from the brighter end of the dish. The other conditions in the Figs. $18 \mathrm{E}$, to $18 \mathrm{~A}$, differ from this case only in degree. By gradual stages the importance of the diffuse light diminishes, and we see the accompanying decrease in the deviation of the animals' paths and centre of grouping.

These results are treated in some detail as they provide an explanation of the discrepancies in the work of some previous investigators who have used graded filters (see p. 424).

Balanus (?) balanoides nauplii. Some observations were made on batches of the latest nauplius stage of Balanus, and the results fit in well with those described above. The filter contained a fairly concentrated solution of ammonia copper sulphate, and the dish was placed as in Fig. 13. The procedure in this case was to place pipette-fulls of larvæ at various points along the side of the dish furthest from the light-source, and to note the mean point of arrival on the opposite side.

In crossing the dish the group continuously spread fanwise. The animals reached the opposite side $(\mathrm{AB})$ over a stretch of a few $\mathrm{cm}$. But they were most numerous about a half-way point, which could be readily determined to the nearest $\frac{1}{2}-\mathrm{cm}$. This point is given in the table below. It represents the average of three trials.

The results are shown in Fig. 15 and in Table III. It is to be noted that the path is all the time deviated to the right-hand side of the course of the direct light-rays. The right-hand side is the side towards the brighter end of the gradient. The amount of deviation tends to increase towards the brighter end. When left undisturbed the larvæ were found to congregate in the middle part of $\mathrm{AB}$, the centre of the group being slightly to the right of the point nearest the source of light (25). With Balanus nauplii, then, a constant deviation is found, which is no doubt to be ascribed to the same cause as noted above, i.e. scattered light from the bright end of the gradient. 


\section{TABLE III.}

\section{Showing Direction of Movement of Balanus nauplit aCross Light Gradient.}

$\begin{array}{cc}\begin{array}{c}\text { Deviation of path } \\ \text { Point } \\ \text { along CD. }\end{array} \\ 5 & \begin{array}{c}5 \frac{1}{2} \text { to } \mathrm{R} . \\ \text { from perpendicular }\end{array} \\ 15 & 3^{\frac{1}{2}}, \\ 25 & 1^{2} \text { to } \mathrm{L} . \\ 35 & 2 \%,\end{array}$

Deviation of direc

light from perpendicular

(cm.).

4 to $\mathrm{R}$.

2 ,,

0 ,

2 to $\mathrm{L}$.

*31 $\frac{1}{2}$,

Caligus rapax ô. An actively photopositive specimen gave particularly clear results in the light gradient (apparatus as in Fig. 13 with ammonia copper sulphate solution in the filter). Crossing the dish rapidly, orientated dorso-ventrally, it moved in a straight course which corresponds well with the direction of the light. It then worked its way along the edge of the glass in a comparatively short time and stopped in the region nearest the light-source. For some time afterwards it remained in the latter region. Its behaviour was in exact accord with the expected behaviour of an animal moving in the direction of the light irrespective of the change of intensity, and thus resembled that of the two species already considered.

When the animal swam on its side, the same menotactic behaviour was observed as noted above (p. 397).

Larvæ of the herring (Clupea harengus). Considerable difficulty was encountered in obtaining clear results from these larvæ, owing in the first place to their tendency to lose activity and ability to orientate well in low intensities of light. But a further complication appeared in the first trials. Active specimens taken from a positive group and placed in the region of C (Fig. 13) first moved, as expected, across the dish approximately in the direction of the light-rays, and then proceeded to work their way along BA towards the centre of the dish. But instead of remaining in the centre they continued to work their way to $\mathrm{A}$. Before long, all active specimens had collected in the dark end of the dish, the majority clustered around D. The procedure was repeated several times, all precautions being taken to eliminate any source of light that might attract positive specimens to corner D. But the results were consistent. Soon the explanation became apparent - most of the larvæ in the darker part of the dish had become negative to light. (That herring larvæ become negative to light of very low intensity was found on other occasions also.) So the only chance of making a successful test with this species was to obtain specimens that had become more adapted to light of low intensity. These were found among larvæ a few days older that were still fit and active. Though it was impossible to reduce the characteristic element of randomness in their movement (see p. 398), the results obtained with them were satisfactory. They moved across the dish roughly in the direction of the light and grouped along $\mathrm{AB}$ on either side of the centre line. The group was widely spread, but not enough to give reason for doubt that the bright end as well as the dark end were being avoided. It was quite clear that, in so far as they exhibited phototactic movement, they followed the direction of the light and did not select the region of highest intensity. Their behaviour therefore is essentially similar to that of other phototactic plankton animals treated here.

Observations on behaviour in the light gradient of several other species,

* Repeated with extra precautions to eliminate scattered light from the sides of the apparatus. The result was the same.

NEW SERIES.-VOL. XIX. No. I. AUGUST, 1933. 
to be mentioned below, were obtained. In all cases the same characteristics were to be seen, namely, movement across the dish in a course approximating to that of the light rays and grouping at the region nearest the light-source. Deviations of the kind described for Centropages and Euterpina were noticed as often as they could have been expected to show.

Acartia clausi grouped somewhat to the right of the path of the direct light (apparatus as in Figs. 12 and 13 and dilute Indian ink in filter). Corycaeus anglicus swam in a characteristic straight course, but there was considerable variation in the direction of the course taken in different trials. Individual paths of Paracalanus parvus also showed variation in direction. This species, at the same time as Acartia, showed tendency to group to the side of the path of direct light (Indian ink in filter). A small Turbellarian moved across the dish in a direct, slightly undulating, path, and gradually worked its way to the region opposite the lightsource ; as did also a Polychæt metatrochophore (apparatus as in Fig. 13 ; ammonia copper sulphate in filter). Other forms include: Temora longicornis, Balanus larvæ, Zoea larvæ, Copepod nauplii, an Autolytid bud with eggs, and some Mollusc larvæ.

Thus, again, all photopositive animals tested showed the same general behaviour.

\section{BEHAVIOUR OF PHOTONEGATIVE SPECIMENS.}

The influence of the direction of the light is particularly well shown by photonegative animals. As ROSE (1925) has noticed at Roscoff, negative specimens in jars of plankton are far less plentiful than positive. And especially is this the case in the low light intensities of the laboratory. The following species are included among the animals that have been studied : Centropages typicus, Calanus finmarchicus, Temora longicornis, and Balanus nauplii, as well as the small bottom-living Harpacticoid, Nitocra typica.

In divergent light, it is characteristic that negative specimens of the animals considered in this paper move away from the source, the mean direction of the course taken being along the path of the light rays. If a beam is passed through the water, animals collected at the light source swim down the beam to the opposite side of the dish, and do not immediately pass to the darker regions. This may be illustrated by the paths taken by negative Temora longicornis, swimming slowly and steadily, orientated away from the source (Fig. 19).

In a parallel beam (apparatus as in Fig. 1), Temora showed similar behaviour, travelling down the beam away from the source. The specimens tested were moving somewhat irregularly, and the course taken 
was consequently rather twisty, but the mean direction was straight in line with the path of the light. Not until after reaching the wall of the dish opposite the source did random movements take them into the darker parts of the dish to the sides of the beam. An excellent example of the same behaviour was provided by some negative Calanus finmarchicus, which, tested individually, swam straight down the beam with steady uniform motion.

The small Harpacticoid, Nitocra typica, a strongly negative species, taken from a bowl in which Amphipods were being reared, also swam down the beam, quite rapidly. The body sways continually, so that the anterior end is always moving from side to side through a wide angle. They first accumulate at the side opposite the source, and then gradually,

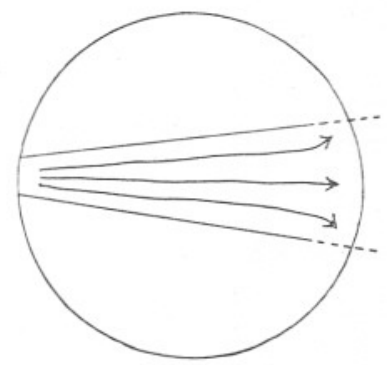

FIG. 19.-Temora longicornis - direction of movement of negative specimens in beam passing through circular dish.

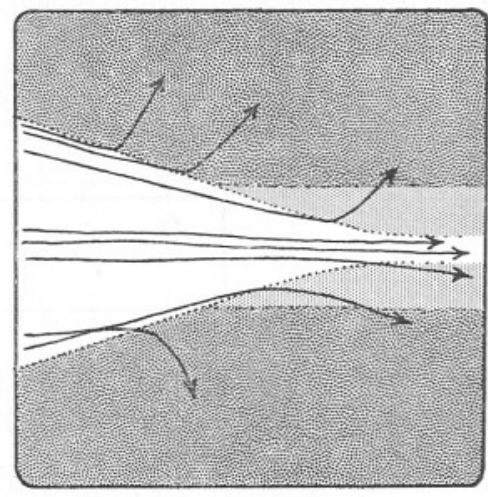

FIG. 20.-Nitocra typica-paths in convergent beam.

through the random component of their movement, work their way to the edges of the beam and into the darker parts of the dish.

More instructive still is the behaviour in a convergent beam. Nitocra typica may be considered first, as numbers were examined at a time. The mean direction of the paths followed is represented schematically in Fig. 20. It will be seen that, so long as the animals remain in the beam, the course followed inclines towards the centre of the dish, while as soon as random movement happens to take the animal clear of the beam, the course bends abruptly to one side. This is just what is to be expected if the direction of the light-rays is followed, and is, indeed, exactly the type of figure that is obtained from photopositive specimens (Fig. 4), only the movement is then towards, instead of away from, the source.

Temora longicornis gave precisely similar results, the individual paths approximating closely to the ideal. They swim in the direction of the rays, and either enter the narrowest part of the beam, or if they approach the edge before this, turn and swim away to the side of the dish. So too 
with Centropages typicus. Again, Calanus finmarchicus swim down the beam in the same way, and show no hesitation on entering the brightest region. Several were observed moving steadily, in a perfectly straight course, following the path of the rays.

Comparable results have been found by KALMUS (1931) to be given by the negative larvæ of Sabellaria spinulosa. The latter move down a convergent beam away from the source and concentrate towards the brightest region.

Behaviour in the light gradient (arranged as in Fig. 13) was studied in the case of Nitocra typica. Specimens placed anywhere along the edge of the dish facing the light (Fig. 21, AB) move across to the opposite side, their course on the average approximating to the direction of the lightrays. (It cannot be said whether deviations such as have been found for

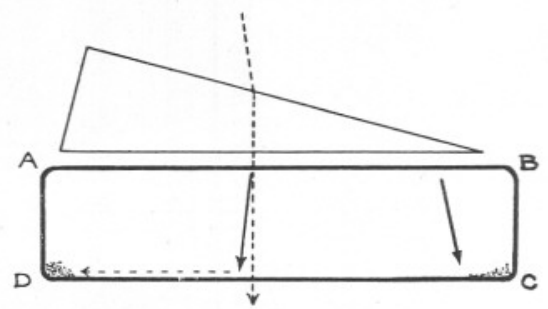

Frg. 21.-Nitocra typica-mean paths and groupings in light gradient. Corners of dish marked $\mathrm{ABCD}$.

some positive forms occur.) Then they gradually congregate towards the right or the left-hand corner, according to which side of the middle line (where the light passes directly across the dish) they may happen to be. There is no congregation in corner $\mathrm{A}$, although the intensity here is scarcely greater than at $\mathrm{D}$, and very much less than at $\mathrm{C}$ : the importance of the direction of the light is once more apparent.

Thus, in all cases studied, the course of negative movement is found to be the exact opposite of that of positive. It would appear that the same orientating mechanisms are involved in both. And just as positive specimens will move into lower intensities as they approach the source, so too negative specimens will move into higher intensities in travelling away from it. The importance of the direction of the light is shown by the fact that negative animals do not take the most direct route to the darker parts of the dish.

\section{SUMMARY OF PREVIOUS WORK.}

\section{Pнототахіs.}

In the foregoing section examples are given of phototactic behaviour observed in marine plankton animals. Examination of the literature 
reveals a considerable number of scattered records of such behaviour. The better attested of these may now be summarised.

COPEPODA. That many Copepods show positive or negative movement to light has long been known (LOEB, 1893; FRANZ, 1911; ESTERLEY, 1919; ROSE, 1925). No attention had, however, been paid to the paths followed by individuals until FRIEDRICH (1931) described observations on the behaviour of Calanus helgolandicus and Corycaeus anglicus in parallel beams of light.

CIRRIPEDIA. The phototaxis of the nauplii of Balanus species has for some time been a favourite subject of investigation (GROOM and LOEB, 1890 ; MOORE, 1909 ; EWALD, 1912 ; ROSE, 1913, 1925). But even with these animals the small size has prevented exact study of the "mechanism" of the behaviour.

$M A L A C O S T R A C A$. The larvæ of Palamonetes vulgaris have been found to move straight to the light source (G. M. WHITE, 1924); so too the strongly reactive Zoeas of Maia squinado (Rose, 1925) and the larvæ of Pinnotheres maculatus (WELSH, 1932).

PROTOCHORDATA. The tadpole larvæ of Amaroucium species move directly, in a close spiral, towards a source of light (MAST, 1921), the orientation apparently being effected by regular shock-reactions in the way Jennings had supposed for Euglena, and not by topotaxis in the true sense. Amphioxus is described by G. H. PARKER (1906) as being negatively phototropic.

PISCES. FRANZ (1910) found that phototactic behaviour is shown to a greater or lesser extent by various fish larvæ, particularly in small vessels, Cyclopterus lumpus and Trachinus vipera being among the most reactive. There are other records of certain fish larvæ collecting towards a source of light, or the reverse; but little, if anything, appears to have been done by way of analysing this movement.

MOLLUSCA. The larvæ of the squid, Loligo pealii, move straight towards a light-source (G. M. WHITE, 1924).

$A N N E L I D A$, etc. Phototaxis has been recorded in Polygordius larvæ (LOEB, 1893), and Spionid larvæ (ROSE, 1925). Tomopteris helgolandica are predominately negative (ROSE, 1925). The negatively phototactic larvæ of Sabellaria spinulosa have been studied in some detail by KALMUS (1931).

PLATYHELMINTHES. Cercaria floridensis moves in the direction of the light (MILLER and McCOY, 1929).

COELENTERATA. YERKES (1903) mentions that the Medusa, Gonionema murbachii, when moving upwards in the water, was subject to the directive action of the light. MURBACH (1909), however, criticises 
this statement, and is of the opinion that the animal never reacts to the direction of the light, but only to changes in intensity.

There are various other instances in which mention is made of positive or negative reaction without further particulars on the relation of the course of movement to the light conditions : e.g. negative $ᄋ \circ$ of Labidocera astiva (G. H. PARKER, 1901); positive Cyprid larvæ of Balanus (VISSHER and LUCE, 1928); Sagitta species (ESTERLEY, 1919).

It may be noted that in several cases the phototactic behaviour has been used as a basis for the elucidation of more special problems involved in light response. Thus LOEB and NORTHROP (1917) used Balanus larvæ for testing the validity of the Bunsen-Roscoe law of resultants in reactions to two sources of light; WHITE (1924) observed the distribution of Palamonetes vulgaris and Loligo pealii in crossing beams of different monochromatic lights; VISSCHER and LUCE (1928), in an admirable piece of work, examined the relative stimulating effects of different wave-lengths by a somewhat similar method in the Cyprid larvæ of Balanus; while WELSH (1932) has measured the effect of temperature and different light-intensities on the rate of swimming in Pinnotheres larvæ. Further, a good deal has been done on the external agencies effective in reversing the "sign," or direction, of taxis (particularly LOEB, 1893 ; ROSE, 1925).

These references should serve to add further evidence to the widespread prevalence, among the smaller free-swimming marine organisms, of phototactic movement; or, at any rate, of the capacity for such behaviour. One important reservation appears necessary, namely, that this generalisation should, at the present state of knowledge, be restricted to bi-laterally symmetrical animals. It is quite doubtful how far radiallysymmetrical animals, such as Medusæ, are influenced by the direction of the light. No experiments on Medusæ are here recorded, partly because they do not survive well, but chiefly because they are not disposed to phototaxis in the manner of other plankton. This, in itself, may be of some significance. Apart from earlier observations on Gonionemus murbachii, there is no help to be obtained from past literature.

With regard to the occurrence of more unusual methods of orientation during phototaxis, two examples among Arthropods may be recalled. In the fiddler-crab, Uca pugnax, strong positive movement towards a light-source is shown. The animal, however, is all the time orientated sideways (HOLMES, 1908). A case somewhat comparable with Acartia clausi is provided by the freshwater larva of the fly Corethra plumicornis, which under certain conditions moves in the direction of the incident light, locomotion being accomplished by a succession of jerks in a direction oblique to the axis of the body at the phase of rest. Movement to light occurs because the jerks are predominately to the most illuminated side, 
and thus are, on the whole, successively to right and left. Thus only accidentally does the animal come to orientate its body exactly in the direction of the light, which, nevertheless, is the average direction of its path.

\section{Analysis of Рнототaxis.}

Very little experimental work has hitherto been published which may help to elucidate the exact nature of the light responses of the animals with which we are concerned. The publications to which reference has been made in the previous section contain only two in which analysis of the phototactic movement has been carried to any length. One of these (KALMUS, 1931) requires further mention, as the experimental methods are of the same kind as those adopted in the work described here. The negative movement of the larvæ of Sabellaria spinulosa was investigated. The behaviour of the larvæ was observed in a convergent beam, between two sources of light, and in a light gradient produced by a wedgeshaped filter. The results are in complete agreement with those obtained here with negative forms (p. 418); and they are such as to satisfy the investigator that the movement is definitely a topotaxis, and not some kind of phobotaxis.

Reference should also be made to a contribution by M. GOLDSMITH (1921), who observed the behaviour of some typical marine plankton animals under the conditions of a light gradient. From the results of this and certain other experiments, she concludes that the reaction to light of these animals is essentially a matter of random movements which bring the animals into a brighter region, and not of orientation to the direction of the light-rays. This is directly contradictory to the results and conclusions stated here, and so requires careful examination. There are good reasons for believing the interpretation to be fallacious, but these are best stated after something has been said of the former work which has involved the use of graded filters.

\section{ON THE USE OF GRADED FILTERS.}

Following Strasburger's classical experiments on the swarm-spores of Algæ (STRASBURGER, 1878; and see ROSE, 1929, p. 15), several workers attempted to apply his method on other photoreactive organisms. The main object was to obtain a gradient of intensity in a contrary direction to the incident light, and to discover whether the animals still moved in the path of incidence, or whether they moved up the gradient towards an optimum intensity. At that time "phototaxis" and "photopathy" were the terms used to describe these alternative forms of behaviour, though the latter expression was susceptible of more definitions than one, and very loosely employed. The term "phototaxis" is 
now used in a wider sense to include all kinds of movement in relation to light, and the sense in which the term was contrasted with "photopathy" is that conveyed in the expression "phototopotaxis."

It seems generally recognised that the results obtained by use of this method have not attained the desired objective. In certain cases, notably among Protista and Crustacea, the organisms appeared to be responsive to the light gradient irrespective of the direction of the rays, and so to exhibit " photopathy." But these cases are each open to suspicion, and indeed have been subjected to criticism both at the time by workers in the same field and by later investigators, such as ROSE (1929). It seems that not only are we without sufficient evidence that "photopathic" behaviour does in fact occur, but, if it does, it may be often open to question whether the light gradient in use could adequately show it. The essential difficulty is that the animals concerned may always be capable of moving in the direction of incidence, and experimental conditions have to be very carefully devised to ensure that, while a sufficiently steep gradient is obtained, apparent " photopathic" effects are not produced as a result of behaviour that is essentially topotactic. This consideration applies especially to a case, dealt with below, in which marine plankton animals are concerned.

At the same time it is not to be implied that experiments with graded filters can give no kind of positive result. The results, for instance, have distinct value if definite topotactic behaviour is still shown; for if the animals still orientate accurately in the direction of the rays, and if they congregate away from the brightest end, as close as they can get to the light-source-just as would happen if no gradient existed-then information is provided on two points: (i) on the independence of topotactic response of gradual changes of intensity in the surroundings, and (ii) on the dominance of topotactic behaviour over any phobotactic behaviour that the animal may be capable of showing. The observations described above (pp. 400-418) should be viewed from this aspect.

It has been seen how various planktonic animals behave in a horizontal light gradient, produced by an Indian ink or ammonia copper sulphate filter, and how the behaviour can be explained completely on the supposition that the animals move in the direction of incidence of the light (and see further the discussion on p. 426 et seq.). It was found that an apparent irregularity was clearly to be explained as the effects of light scattered and reflected from the brighter end of the gradient. With Indian ink in the filter the latter effects increased as the mixture was made more concentrated, until, under the conditions represented in Fig. $18 \mathrm{c}$, the animals grouped close to the brighter end of the gradient. The disturbing effect of scattered light was also sometimes observed, though to a less extent, with the copper solution in the filter. 
These results render intelligible M. GOLDSMITH'S observations (1921). She gives a brief report on the use of a gradient-apparatus, consisting of a dish painted over with black varnish and covered with a piece of smoked glass of graded opacity. No light could enter the dish except through the cover, which thus acted as a graded filter. The dish was placed near an electric light shining obliquely down on it, with the darkest end of the cover nearest the light. Thus the end of the dish nearest the light was situated at the darkest end of the gradient. Goldsmith's results may be quoted in full :-

“Les Convoluta, les Mysis, les zoé de Maia se groupaient en très grande majorité (il faut noter que l'éclairement était assez faible) dans la partie la plus transparente du vase, qui est en même temps la plus éloignée de la source. Pour les Copépodes planktoniques, il en est de même à la lumière solaire ; à la lumière électrique, la région optima se trouve à mi-chemin entre les deux extrémités du vase."

Considering that the smoked glass must have scattered the light very considerably, the result is quite in harmony with the present observations, and accordingly is not in any way inconsistent with the idea that the animals' response could have been purely topotactic. For one would have expected at any rate the zoeas and Copepods to follow in the mean direction of the light-rays, and the fact that they are brought into the brighter half of the vessel is almost certainly due to the effects of scattered light. The above results are thus essentially comparable with those obtained by DAVENPORT and CANNON (1897) with Daphnia, and E. TOWLE (1900) with Cypridopsis. (Both of these investigators deal with light shining on the filter obliquely from above, and in both cases the animals clearly move in the direction of incidence of the light.)

M. Goldsmith, however, felt justified in the conclusion that the reactions to light of the animals she observed do not consist in orientation to the direction of the light-rays depending on a symmetrical influence of the light, but in various random movements which bring them into the brightest region. This verdict is remarkable considering that the animals included such strikingly phototactic forms as Balanus nauplii, Centropages hamatus, Acartia clausi, Zoeas of Maia squinado, etc. Actually it is based on two main pieces of evidence : one has already been adequately dealt with by ROSE, who has carried the experiment in question a stage further, and simply demonstrated that the results are otherwise explicable (1929, pp. 152-153) ; the other piece of evidence is from the behaviour in the light gradient, and this, in view of the above considerations, is seen to be invalid.

With respect to other work involving the use of graded filters, especially that on freshwater Crustacea, it seems likely that if the results were 
considered in the light of the criticism applied above, some of the apparent inconsistency would be removed. It may be legitimately doubted whether any of the so-called photopathic effects (YERKES, 1899; DITLEVSEN, 1907) are anything but the result of topotactic movement. Still it may be significant that YERKES found a complete contrast in the behaviour of Cyclops parvus ("phototactic") and Simocephalus vetulus ("photopathic") under the same conditions.

\section{INTERPRETATION OF THE RESULTS.}

It is now necessary to consider what the observations described in this paper, together with previous work along similar lines, may have succeeded in demonstrating. Our procedure, it may be recalled, has been to observe behaviour under different conditions of illumination designed so that the intensity gradient and the direction of incidence bore different relations to one another. In other words, the data include $(a)$ conditions of illumination described as a character of the physical environment, and $(b)$ the behaviour of the animals in relation to $(a)$. It is necessary to be clear on this point when, later, consideration is given to the sensory responses of the animals in question; for the light conditions as "appreciated" by the animal may differ considerably from those thus described, owing to the specialisation of the light-receptors.

\section{Where the Groups Form.}

The results on pp. $400-418$ show that in no case did positive animals group in the brightest region when this was away from the point nearest the light-source. In a convergent beam, groups always settled at the entrance of the beam, and not in the narrowest, brightest, part. Though fewer species have been tested in the light-gradient, the results obtained were quite consistent (p. 418). The group collected away from the brighter end somewhere in the region opposite the light-source, or, more strictly, in the region of the "axial line" at which the direct light from the source passes across the dish at right angles. This "axial line" in the dish can be found in a simple way by interposing a screen with a narrow slit. It is of significance in that it represents the line along which the direct light is equally balanced on both sides (at least as detectable by a sufficiently small photoreceptive mechanism).

It is to be noted, however, that the groups do not usually form exactly round this point, but at a greater or lesser distance towards the brighter end of the dish. It has been seen how this effect is undoubtedly due to scattered light, of which considerably more will come from the brighter end than the darker, depending on the nature and concentration of the 
solution in the filter. This scattered light will result in shifting the effective " axial line" a little way towards the brighter end.

One may speak of an " effective axial line," defined practically in some such way as follows. Supposing suitable methods of measurement were devised, small arrows could be placed in various parts of the dish indicating the direction in which the light falling on the two sides of the arrow is equal in amount. If one imagines that these arrows are liberally distributed and placed in horizontal rows, it is easy to see that in each row, somewhere near the region of the point close to the light-source, one arrow will point at right angles to the long axis of the dish. A line joining such arrows is what is understood by the expression "effective axial line" (see Fig. 22). It may be straight, or somewhat curved, but in any case

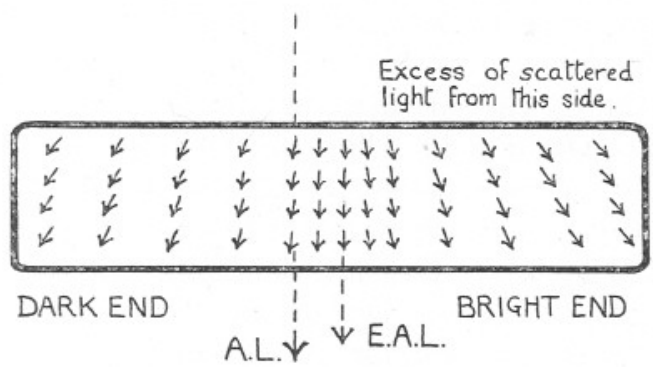

FIG. 22.-Light conditions in light gradient apparatus. At each point the direction of the light is the resultant of two components: (i) direct light from source, (ii) excess scattered light from bright end.

A.L., axial line. E.A.L., effective axial line.

it will be nearly, if not quite, at right-angles across the dish, a little to the side of the simple straight axial line of the direct light.

We are now in a position to define more precisely the position at which the group forms. If the effects of scattered light were quite negligible, one would expect it to form about the direct axial line ; since, however, they are not, the group instead forms about the "effective axial line." This appears to express adequately the observed behaviour of those animals tested in the conditions of the light gradient.

To state the evidence provided by these results more generally : positive groups of the plankton organisms investigated primarily collect around a point in the mean line of incidence of the light. The point in the line will of course be that beyond which the confines of the vessel prevents the animals from passing. It is immaterial whether this happens to be the brightest region of the dish accessible, or not. The amount of scattering of the group on either side of the point will vary with the degree of diffuseness of the light. Negative forms show just the expected reverse behaviour. 


\section{Behaviour of Individuals.}

How the groups come to collect in the above way is explained by examination of the behaviour of the individuals composing them. When the movement of individuals is considered, two points emerge clearly enough.

First, the various animals tested were able to maintain their normal movement in the direction of incidence of the light, whatever the changes of total intensity encountered during their passage. As they moved up a convergent beam, and as they moved towards the axial line in the gradient dish, the intensity was diminishing. The removal of the intensity factor did not noticeably affect their capacity for movement in the direction of the light-rays. Secondly, if the animals have opportunity of " selecting " one of two paths, namely either one of increasing intensity or one in the path of incidence of the light, they will chose the latter.

An animal following the path of incidence will, on the average, maintain an equal balance of the light falling on the two sides of the body, or, strictly speaking, of its photoreceptive surfaces. It is this orientation, exact or approximate, of their path that brings these animals into illuminated regions. They first cross the dish in the path of the rays, and then work their way along the side towards the "effective axial line." The latter phase is naturally the slowest, as the animals are continually moving against the glass, and it is only the excess of random movements in one direction that enables them to progress. At the " effective axial line" random movement in either direction is equally probable; hence the animals accumulate here. It can now be fully appreciated why the groups form in the positions in which they have been found.

\section{Nature of the Phototactic Movement.}

Looking further into the observations on the behaviour of individuals, we may enquire how far the characteristic behaviour of species observed fits into any of the five categories distinguished above (pp. 388-9). This is a matter of more than academic interest, in that if an animal can be assigned definitely to one of these categories, various predictions as to its behaviour become possible. There will, for instance, be an opportunity for speculating what it does in the sea.

In this procedure we are faced with the question, hitherto evaded, as to how the light conditions are to be viewed from the aspect of the animal. So far we have considered the light conditions as a character of the physical environment, for as such they can be measured and described in a straightforward manner. They can be mapped out in a framework representing dimensions of space and time, total intensity indicated by contours and mean direction by a series of arrows. But the simplicity of this scheme is, 
after all, only because it is, operationally considered, an idealised construction. The specified light conditions of a point within this optical field mean nothing if it is not that they are to be detected by an object placed at that point. And the optical field, described as above, actually represents the conditions of illumination detectable by a hypothetical photometer that is sensitive to light from all directions equally, and is ideally small.

If we regard light-sensitive animals in their capacity of photoreceptive mechanisms, we can discover how they tend to differ from the abovementioned hypothetical photometer. And we find that the chief difference is that they may by no means be sensitive to light from all directions equally. With motile, bilaterally symmetrical animals, it is generally the case that photoreceptor organs are concentrated at the anterior end and may be largely, if not altogether, shaded from the light falling on the posterior surfaces. Of course the degree to which this happens varies among different forms, but the general tendency is beyond dispute. With such specialised distribution of light-sensitivity over its surface, a photoreceptive mechanism loses its ability to record the changes of light intensity that occur in its surroundings, unless provision is made to allow for its direction of orientation. For now it will record different intensities at the same position according to the direction in which it is facing-as, to take an extreme example, a camera placed at a given point in the beam of a motor head-lamp. We can therefore see, in the first place, how a change of intensity recorded by the animal will be a combination of the change in the physical field and that due to change in orientation of the body in relation to the main source; and, in the second place, how the resultant direction of the light may also vary-according to the dominance in stimulating fower of light falling along the axis of bodyorientation over that falling laterally.

All this is to show how the light conditions capable of stimulating an animal as it passes through an optical field may by no means coincide with those reproducible by an ideally small photometer, that is, with the light conditions of the environment stated in physical terms. The animal is here regarded purely in its capacity of an automatic light recorder. It should not, however, be overlooked that further " complications " may be expected from such phenomena as threshold stimulation and state of adaption of the sense-organs; while, on the other hand, even if the light conditions appreciated may not coincide well with those of the physical surroundings, the behaviour of the animal may be so adapted that its movements will nevertheless be such as to compensate for the difference.

Applying these considerations to the special problem of phototaxis, it becomes apparent that the behaviour observed in the convergent beam 
and in the light gradient (i.e. direction of light chosen against intensity gradient) is not a conclusive proof of topotaxis (III $a$ and $b$, p. 388). It is conceivable that an animal could follow such a path merely by reacting to changes in intensity affecting its sensitive area as a whole owing to small deviations in the direction of orientation of its body, or of its sensitive anterior end. It might all the time be avoiding movement into a position which, to it, involves decrease of illumination. Such behaviour would be classed under $(c)$, and justifiably termed phobotaxis, although the resulting path the animal follows may be well directed towards the source.

To distinguish this behaviour from true topotaxis is not simple, for in many respects the net result will be identical. But certain distinctions are bound to follow. First may be mentioned a characteristic that provides a useful laboratory expedient for distinguishing between the two types. Unilateral blinding results in circus movements in the first case, not in the second. On these grounds HERTER (1926) has good evidence that Nereis diversicolor is enabled through its hind ocelli to move topotactically, but if these are put out of action and the front ocelli left intact, the worm still orientates, though less accurately, by this phobotactic method. In the second place, orientation is evidently more difficult in phobotaxis, and considerable deviations from the mean path are to be expected. Also where movement is not in a spiral path, it is difficult to see how this method of orientation could work at all without considerable side to side movement of the head. It is evidently to be ruled out of the question if the animal orientates accurately towards the source of light and proceeds to move straight towards it without any side movements, as may be observed in the case of most Copepods and various larvæ of Decapods. A further consideration is applicable to an animal which can maintain a fairly well directed path phobotactically; for it follows that the light intensity it appreciates varies greatly with the position of the body. If it should happen to move into an intensity that is too strong, it has only to turn its body slightly to the side to reduce the appreciated intensity considerably. It could therefore achieve the same result by merely turning the body as by moving further away from the source. Clearly, then, an animal of this kind would encounter difficulties in keeping within an optimum zone of intensity. Thus, paradoxically, an animal sufficiently sensitive to changes in intensity to maintain a path directed towards a source, would not easily arrive at a region where the intensity is " optimum."

Returning now to the interpretation of the observed behaviour, we may recall that all cases dealt with are to be classed as taxis (III, p. 388). We may further state that no behaviour remotely suggesting $(e)$ or $(d)$, (p. 389) was noticed; and since all the species moved to, or from, the light in a more or less well-directed path, $(b)$, too, is of no account. The latter 
condition is indeed sometimes approached by animals which normally move in a straight course, but which, for some reason or other, are not reacting well.

We are therefore left with alternatives $(a)$ and $(c)$. Something has already been said of the distinctions between these two modes of behaviour. It may be repeated that any animal maintaining accurate orientation and moving in a straight line in the direction of incidence, with no sideways or "searching" movements, cannot possibly be classed under $(c)$. True topotaxis is, therefore, exhibited by :-

$\begin{aligned} \text { various Copepods : } & \text { Centropages typicus } \\ & \text { Temora longicornis } \\ & \text { Paracalanus parvus } \\ & \text { Corycaeus anglicus } \\ & \text { Caligus rapax } \hat{\jmath}\end{aligned}$

Decapod larvæ: Galathea spp.

Upogebia sp.

Pandalus montagui

Zoea larvæ of Porcellana sp. and other crabs

Cirripede metanauplius

At least some Polychæt larvæ.

These animals are presumably capable of appreciating differences between light falling on the right and left sides, and of adjusting their position so that the intensity is equally balanced. It is of interest to note that whereas the Decapod larvæ possess paired compound eyes of some size, Calanoid Copepods have but a small single median eye. Yet for slow movement the latter are capable of orientating with considerable accuracy. Corycaeus anglicus has large paired lenses focussing on small paired eyes, and it is evident that the light falling straight from the direction in which the animal happens to be facing will be far more effective than that falling laterally or from behind. That this is actually the case is indicated by certain features of the animal's behaviour.

The species in the above list, as well as others, which, as emerges later, should be classed with them, may be expected to exhibit characteristics which appear to be generally typical of topotactic behaviour: for instance (i) ready reversal from positive to negative, and vice versa, under the influence of appropriate stimulation, such as temperature change, chemical change, mechanical shock, increase of light-intensity, etc.; (ii) movement in a diagonal line between two light sources, or movement in the resultant line when the light is falling from various directions or greatly scattered. Such behaviour has actually been tested and observed in several of the above species. Corycaeus anglicus is less inclined than 
others to keep to a diagonal between two sources, owing without doubt to the fact that its lenses are so constructed as to concentrate light from one direction.

It may also be noted that when the light is broken up and made to fall from various directions, the paths are more varied, and the groups formed more scattered, but the average direotion of movement approximates to the direction from which the greatest amount of light is coming and on either side of which the total amount of light is fairly equalised.

Two other cases of topotaxis stand quite on their own. First, the strongly positive Acartia clausi is, as we have seen, capable of moving in a reasonably straight path in the direction of a light-source, without keeping its body orientated in any fixed direction. Movement is in " jerks," and successive " jerks" are not necessarily in the same direction, so that the course is somewhat zig7ag (see p. 396). During movement the body may be orientated in almost any direction, though positions in which the anterior end is above the lower are most frequent. The appearance is as though the animal were being forcibly pulled to the light in whatever direction it attempted to move. The fact that Acartia moves likewise in the path of incidence of the light in a convergent beam and across a light-gradient proves that the animal is not reacting to changes in intensity-i.e. its phototaxis is not type $(c)$; for its transparent body and constant body-orientation ensure that it is affected by light from all directions fairly equally. The movement is thus a variety of true topotaxis, but how exactly this is brought about presents a problem that cannot be answered by the usual interpretations of this category of behaviour. Secondly, Poecilochaetus serpens, writhing vigorously, so that no part of its body has any constant relation to any other part, is able to move straight up a beam of light (p. 399). Again we are presented with the phenomenon of orientation of the path in absence of orientation of the body.

It appears, then, a distinction should be drawn between cases of true topotaxis in which orientation of the path is the result of orientation of the body, and those in which it is not. That cases of the latter type should occur at all is of some interest, and the fact by no means simplifies the theory of phototaxis. Perhaps it occurs more frequently than may be suspected. It has been noted (p. 398) how a Pandalus larva moved straight up a beam although orientating at various oblique angles.

The foregoing paragraphs deal with clear examples of true topotaxis (Type $a$ ), which stand out because of the accuracy with which orientation can be effected. Since a number of such examples occur, one may confidently expect to find along with them many others in which orientation is not so efficient, though effected in essentially the same way. The animals, though exhibiting true topotaxis, will not keep such a straight 
course. There can be little doubt that the bulk, if not all, of the other species referred to fall into this class. For instance :-

Copepoda : all species in more rapid movement

Euterpina acutifrons

Nitocra typica

Cirripedia : Balanus nauplii

some Polychæt larvæ

Decapod larvæ.

Thus the whole range of species investigated is practically covered; and the evidence is strong that true topotaxis $(a)$ is the primary type of response of these animals to light.

But whatever closer study on the distinction between $(a)$ and $(c)$ may show, it is for most purposes sufficient that the animals examined fall into one or other of these categories. For it means that all have one important characteristic in common. That is, that the response to light is such that movement is always in the direction of the rays. The influence of the direction of incidence is such that the changes of light intensity encountered during progress are of no significance with respect to direction of movement. That this statement should not be misunderstood, it is perhaps necessary to point out that it is by no means implied that changes of intensity have no influence at all. Such would be contrary to fact. Reactions, for instance, may occur to sudden changes, such as when an animal enters a beam or a shadow; movement may be activated or inhibited by variation in light intensity, or the direction of phototaxis reversed. And since in nature the animals are subject to sudden shadowing, to fairly rapid changes at dawn and dusk, and to increase in lightintensity as they move upwards in the direction of incidence, such behaviour is undoubtedly of importance. The point, however, with which we are here concerned is that changes in intensity in the environment are of no significance for the maintenance of the sort of phototactic movement that a wide range of plankton animals show. The path of the animal is orientated in the direction from which the light is coming, or, if the light is scattered and falling from various directions, to the resultant of the total incident light. And whether the actual mechanism of this movement is that of class $(a)$ or class $(c)$, the general course of movement is the same.

These conclusions are based primarily on the observations here described, but they also receive some support from those that are to be found in the literature. It may be pointed out that, in general, observers of the behaviour of plankton animals have been struck by the apparent topotactic nature of characteristic light responses. In particular, reference should be made to M. ROSE (1925, 1929), who has paid as much attention to this subject as anyone. One gathers from his publications 
that he regards the directional properties of the light as of primary significance. The experimental evidence here provided justifies this opinion.

\section{RELATION TO THE PROBLEM OF VERTICAL MIGRATION.}

It is not unreasonable to assume that the animals exhibit the same kind of response in the sea as in the laboratory, though the extent, or the intensity, or the persistence may differ in the two cases. If this is so, then movement in the direction of the incident light, whether positive or negative, should at least figure prominently among the light responses of the animals in nature.

Accurate field-work, in which a valuable lead has been given by F. S. Russell, is showing that movements of the plankton are related to changes in the light conditions more readily than to any other environmental factor. Some species, indeed, tend to "follow" an optimum intensity. In so far as this is the case, we can now point to topotactic behaviour as one important means whereby such an "optimum " is reached. Positive topotaxis is of itself sufficient to bring animals from low intensities up towards their " optimum," and may alone be adequate to keep persistently positive forms such as Acartia clausi high in the water. When the light-intensity increases beyond the "optimum," one must suppose, in so far as light conditions regulate behaviour, either that the animals become negatively topotactic (Loeb's original theory), or that movement is inhibited and the animals sink back into their "optimum " zone (as first put forward by EWALD, 1912). Be that as it may, the prevalence of the kind of orientated movement to which prominence has here been given, could account in a large measure for the correlations that are found between vertical distribution and light-intensity.

\section{SUMMARY.}

1. The most noticeable response of marine plankton to light, under laboratory conditions, is the formation of groups on the lighted (or opposite) side of the vessel containing them.

2. Specimens from such groups were tested under different conditions of illumination, and in all cases they moved in the direction of the light quite irrespective of accompanying changes of intensity in the surroundings.

3. Groups form around the line of direction of the light, or the resultant direction when the light is scattered or falling from more directions than 
one, this being the direct result of individuals moving along the mean path of incidence of the light.

4. The behaviour of individuals was examined more closely to distinguish between the two possible ways in which the directed movement could have been brought about, viz. (i) reactions to bilateral inequalities of illumination (here called "true topotaxis "), and (ii) reactions to changes in total illumination of light-receptors (a type of "phobotaxis"). For a number of species it was clearly a case of "true topotaxis," and very probably for at least the majority of the rest.

5. In two very different cases, namely, Acartia clausi and Poecilochaetus serpens, there was no orientation of the body, but nevertheless efficient orientation of the path of movement. It is believed that this is the first occasion on which such behaviour has been described.

6. The observations described point to the fact that movement in the direction of incidence of the light, however this may be affected, is general among a wide range of the smaller, free-living, bilaterally symmetrical, marine animals, and would tend to dominate other possible response to light. This behaviour on the part of individuals provides a substantial basis for attempted explanations of the correlations, that have been demonstrated by ecological workers, between the vertical distribution of populations and light-intensity.

\section{REFERENCES.}

Bancroft, F. W., 1913. Heliotropism, differential sensibility, and galvanotropism in Euglena. Journ. Exp. Zool., Vol. XV, pp. 383425.

Davenport, C. B., and Cannon, W. B., 1897. On the determination of the direction and rate of movement of organisms by light. Journ. Physiol., Vol. XXI, pp. 22-32.

Dituevsen, H., 1907. Versüche über das Verhaltnis einiger Planktontiere gegenüber Licht. Skand. Arch. f. Physiol., Bd. XIX, pp. 241261.

Esterly, C. O., 1919. Reactions of various plankton animals with reference to their diurnal migrations. Univ. Calif. Publ. Zool., Berkeley, Vol. XIX, No. 1, pp. 1-83.

Ewald, W. F., 1912. On artificial modification of light reactions and the influence of electrolytes on phototaxis. Journ. Exper. Zool., Vol. XIII, No. 4, pp. 591-612.

Fraenkel, G., 1931. Die Mechanik der Orientierung der Tiere im Raum. Biol. Reviews, Camb. Phil. Soc., Vol. VI, pp. 36-87. 
Franz, V., 1910. Phototaxis und Wanderung nach Versuchen mit jungfischen und fischlarven. Int. Rev. Hydrobiol. Hydrogr., Bd. III, pp. 306-334.

1911. Weitere Phototaxis Studien. Ibid., Bd. III, Suppl., pp. 1-21.

Friedrich, H., 1931. Mitteilungen über vergleichende Untersuchungen über den Lichtsinn einiger mariner Copepoden. Zeit. Vergleich. Physiol., Bd. XV, pp. 121-138.

Goldsmith, M., 1921. Les réactions phototropiques de quelques animaux marins. C. R. Acad. Sci., Paris, t. CLXXIII, pp. 206-208.

Groom, T. T., and Loes, J., 1890. Der Heliotropismus der Nauplien von Balanus perforatus und die periodischen Tiefwanderungen pelagischer Tiere. Biol. Centralb., Bd. X, pp. 160-177.

HARPer, E. H., 1907. The behaviour of the phantom larvæ of Corethra plumicornis Feb. Jour. Comp. Neur. \& Psychol., Vol. XVII, pp. 435456.

Henschel, J., 1929. Reizphysiologisch Untersuchungen an der Käsemilbe Tyrolichus casei Oud. Zeit. Vergl. Physiol., Bd. IX, pp. 802 837.

Herter, K., 1926. Versuche über die Phototaxis von Nereis diversicolor O. F. Mull. Zeit. Vergl. Physiol., Bd. IV, pp. 103-141.

Holmes, S. J., 1908. Phototaxis in fiddler crabs and its relation to theories of orientation. Jour. Comp. Neur. \& Psychol., Vol. XVIII, pp. 493497 .

Jennings, H. S., 1906. Behaviour of the lower organisms. New York.

Kalmus, H., 1931. Bewegungsstudien an den larven von Sabellarai spinulosa Leuck. Zeit. Vergl. Physiol., Bd. XV, pp. 164-192.

KüHN, A., 1919. Die Orientierung der Tiere im Raum. Jena.

Loes, J., 1893. Uber künstliche Umwandlung positiv heliotropischer Tiere in negativ heliotropische und umgekehrt. Arch. Ges. Physiol., Bd. LIV, pp. 81-107.

— 1918. Forced movements, tropisms, and animal conduct. Philadelphia and London.

Loeb, J., and Northrop, J. H., 1917. Heliotropic animals as photometers on the basis of the validity of the Bunsen-Roscoe law for heliotropic reactions. Proc. Nat. Acad. Sci., pp. 539-544.

Lyon, E. P., 1906. Note on the heliotropism of Palæmonetes larvæ. Biol. Bull., Vol. XII, pp. 23-25. 
Marine Biological Association, 1931. Plymouth Marine Fauna. Second edition. Plymouth.

Mast, S. O., 1921. Reactions to light in the larvæ of the Ascidians, Amaroucium constellatum and $A$. pellucidum, with special reference to photic orientation. Journ. Exp. Zool., Vol. XXXIV, pp. 149-188.

Miller, H. M., and McCoy, O. R., 1929. An experimental study of the behaviour of Cercaria floridensis in relation to its fish intermediate host. Carnegie Inst. Year Book, Vol. XXVIII, pp. 295-297.

Moore, B., 1909. Reactions of marine organisms in relation to light and phosphorescence. Trans. Liverpool Biol. Soc., Vol. XXIII, p. 19.

Müller, A., 1925. Ueber Lichtreactionen von Landasseln. Zeit. Vergl. Physiol., Bd. III, pp. 113-143.

Murbach, L., 1909. Some light reactions of the medusa, Gonionemus. Biol. Bull., Vol. XVII, pp. 354-358.

Parker, G. H., 1901. The reactions of Copepods to various stimuli, and the bearing of this on the problem of daily depth migrations. Bull. U.S. Fish. Comm., Vol. XXI, pp. 103-123.

1906. On the reactions of Amphioxus to light. Proc. Soc. Exp. Biol. \& Med., Vol. III, pp. 61-62.

Patten, B. M., 1914. A quantitative determination of the orientating reaction of the blowfly larva. Journ. Exp. Zool., Vol. XVII, pp. 213280.

Rose, M., 1913. Recherches biologiques sur le plankton (deuxième note). Bull. Inst. Océan. Monaco, No. 276.

- 1924. - (5

1925. Contribution à l'étude de la biologie du plankton. Arch. Zool. Exp. et Gén., t. LXIV, pp. 387-542.

1929. La Question des Tropismes. Paris.

Russell, F. S., 1925. The vertical distribution of marine macroplankton. An observation on diurnal changes. Journ. Mar. Biol. Assoc., Vol. XIII, N.S., pp. 769-809.

1926. The vertical distribution of marine macroplankton. IV. The apparent importance of light intensity as a controlling factor in the behaviour of certain species in the Plymouth area. Ibid., Vol. XIV, N.S., pp. $415-440$.

1927. The vertical distribution of plankton in the sea. Biol. Reviews, Camb. Phil. Soc., Vol. II, pp. 213-262. 
Strasburger, E., 1878. Die Wirkung des Lichtes und der Wärme auf Schwarmsporen. Jena. Zeit., N.F., Bd. XII, pp. 551-625.

Towle, E., 1900. A study in the heliotropism of Cypridopsis. Amer. Journ. Physiol., Vol. III, pp. 345-365.

Visscher, J. P., and Luce, R. H., 1928. Reactions of Cyprid larvæ of barnacles to light with special reference to spectral colours. Biol. Bull., Vol. LIV, pp. 336-350.

WELSH; J. H., 1932. Temperature and light as factors influencing the rate of swimming of larvæ of the mussel crab, Pinnotheres maculatus Say. Biol. Bull., Vol. LXIII, pp. 310-326.

White, G. M., 1924. Reactions of the larvæ of the shrimp Palcomonetes vulgaris and the squid Loligo pealii to monochromatic light. Biol. Bull., Vol. XLVII, pp. 265-272.

Yerkes, R. M., 1899. Reaction of Entomostraca to stimulation by light. Amer. Journ. Physiol., Vol. III, pp. 157-182.

- 1900. Reactions of Daphnia and Cypris. Ibid., Vol. IV, pp. 405422.

1903. A study of the reactions and reaction-time of the Medusa Gonionemus murbachii to photic stimuli. Ibid., Vol. IX, pp. 279-307. 